NATIONAL LABORATORY

\title{
Error Reduction for Weigh-In-Motion
}

July 25, 2008

\author{
Prepared by \\ L. M. Hively \\ R. K. Abercrombie \\ M. B. Scudiere \\ F. T. Sheldon
}

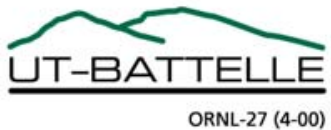




\section{DOCUMENT AVAILABILITY}

Reports produced after January 1, 1996, are generally available free via the U.S. Department of Energy (DOE) Information Bridge.

Web site http://www.osti.gov/bridge

Reports produced before January 1, 1996, may be purchased by members of the public from the following source.

National Technical Information Service

5285 Port Royal Road

Springfield, VA 22161

Telephone 703-605-6000 (1-800-553-6847)

TDD 703-487-4639

Fax 703-605-6900

E-mail info@ntis.gov

Web site http://www.ntis.gov/support/ordernowabout.htm

Reports are available to DOE employees, DOE contractors, Energy Technology Data Exchange (ETDE) representatives, and International Nuclear Information System (INIS) representatives from the following source.

Office of Scientific and Technical Information

P.O. Box 62

Oak Ridge, TN 37831

Telephone 865-576-8401

Fax 865-576-5728

E-mail reports@osti.gov

Web site http://www.osti.gov/contact.html

This report was prepared as an account of work sponsored by an agency of the United States Government. Neither the United States Government nor any agency thereof, nor any of their employees, makes any warranty, express or implied, or assumes any legal liability or responsibility for the accuracy, completeness, or usefulness of any information, apparatus, product, or process disclosed, or represents that its use would not infringe privately owned rights. Reference herein to any specific commercial product, process, or service by trade name, trademark, manufacturer, or otherwise, does not necessarily constitute or imply its endorsement, recommendation, or favoring by the United States Government or any agency thereof. The views and opinions of authors expressed herein do not necessarily state or reflect those of the United States Government or any agency thereof. 
ORNL/TM-2008/004

Computational Sciences and Engineering Division

\title{
ERROR REDUCTION FOR WEIGH-IN-MOTION
}

\author{
L. M. Hively \\ R. K. Abercrombie \\ M. B. Scudiere \\ F. T. Sheldon
}

Date Published: July 2008

\author{
Prepared by \\ OAK RIDGE NATIONAL LABORATORY \\ Oak Ridge, Tennessee 37831-6283 \\ managed by \\ UT-BATTELLE, LLC \\ for the \\ U.S. DEPARTMENT OF ENERGY \\ under contract DE-AC05-00OR22725
}





\section{CONTENTS}

Table of Contents

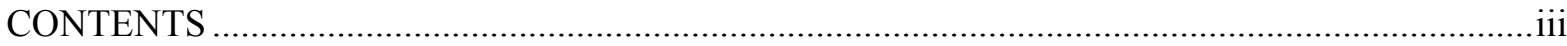

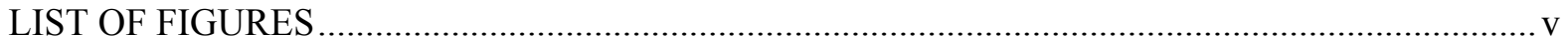

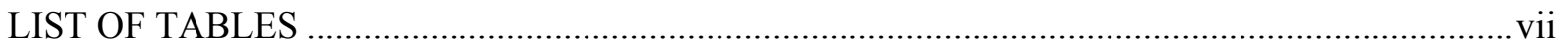

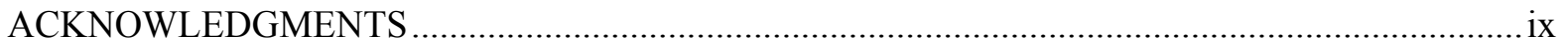

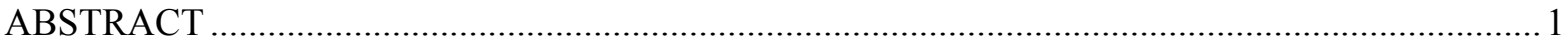

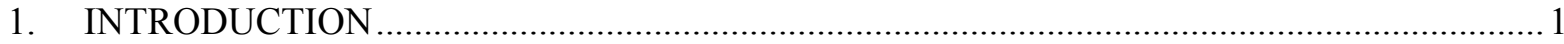

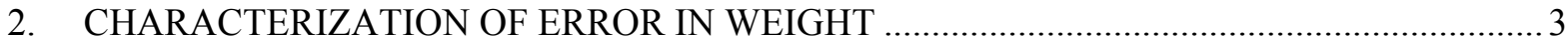

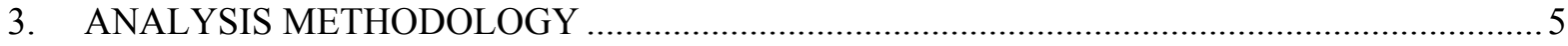

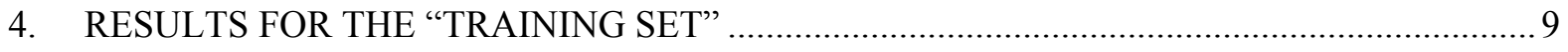

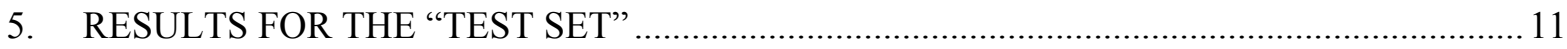

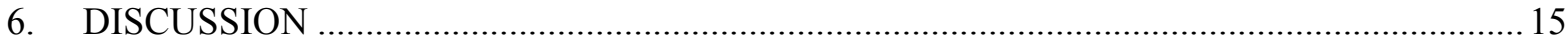

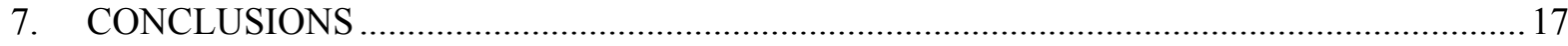

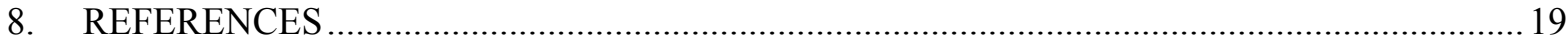

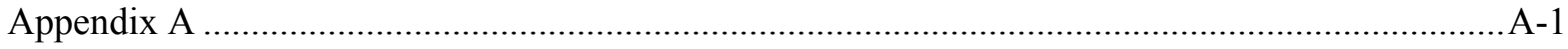

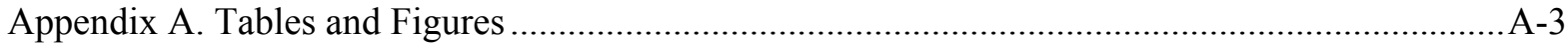

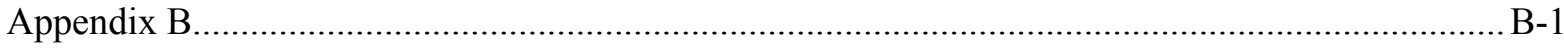

APPENDIX B: Mathematical Details of WIM Analysis ............................................................... B-3 



\section{LIST OF FIGURES}

Figure

Page

Figure 1. Weight measurement components and communication interfaces. .............................. -17

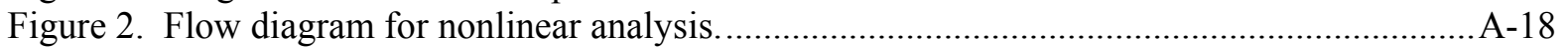

Figure 3. Time-serial weight measurements versus time. .......................................................

Figure 4. Decrease in residual (filtered) WIM error versus mode number....................................A-20

Figure 5. Average percent error in the WIM vehicle weight versus vehicle speed........................A-21

Figure 6. (WIM weight)/(IGS weight) versus IGS weight....................................................

Figure 7. Raw Weight Data for Hummer-BB06 Dataset.............................................................

Figure 8. Sample standard deviation in the total WIM weight versus the time lag between the frontand rear-axle datasets for the Caravan-02 dataset without any clear minimum ............................. A-24 Figure 9. Sample standard deviation in the total WIM weight versus the time lag between the frontand rear-axle datasets for the F250-01 dataset with a clear minimum. ......................................... A-25

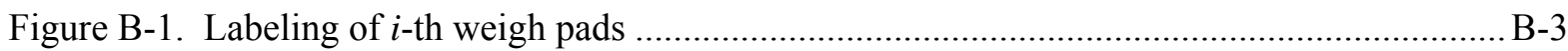

Figure B-2. Locations of eight load cells in each WIM weigh pad................................................ B-7 



\section{LIST OF TABLES}

Table

Page

Table 1. Time and motion study results. A-3

Table 2. Percent error (16 vehicle configurations between 5,600 and 70,000 pounds) A-3

Table 3. Mode parameters for wrecker 6 analysis (item 12 of table 2). A-4

Table 4. Unfiltered error, e(u), and filtered error, e(n), in training sets A-5

Table 5. Characterization of test datasets. A-5

Table 6. Mode-removal results for each wheel crossing of F-250 vehicle A-6

Table 7. Mode-removal results for each wheel crossing of freightliner truck A-7

Table 8. Mode-removal results for each wheel crossing of hummer $\mathrm{H} 3$ vehicle.....................................

Table 9. Mode-removal results for each wheel crossing of silverado vehicle ........................................A-9

Table 10. Occurrence rate of error below $0.1 \%$ for single-wheel-crossing data.................................A-10

Table 11. Occurrence rate of outliers for single-wheel-crossing data..................................................

Table 12. Comparison of IGS and WIM from single-wheel crossings (pounds) .................................

Table 13. Mode-removal results for each axle of F-250 vehicle .........................................................A-11

Table 14. Mode-removal results for each axle of freightliner truck ....................................................

Table 15. Mode-removal results for each axle of Hummer H3 vehicle ................................................13

Table 16. Mode-removal results for each axle of Silverado vehicle....................................................14

Table 17. Occurrence rate of error below $0.1 \%$ for single-axle data .....................................................15

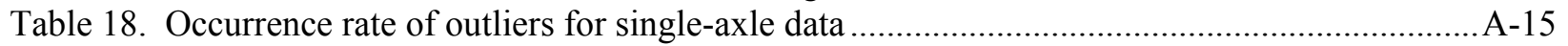

Table 19. Comparison of IGS and WIM for single-axle data (pounds) .............................................. 15

Table 20. Whole-vehicle, mode-removal results for F-250 vehicle ................................................ A-16

Table B-1. Summary of WIM results.................................................................................................. B-11 



\section{ACKNOWLEDGMENTS}

We gratefully acknowledge funding of this work by the ORNL Office of Technology Transfer's Technology (OTT) Maturation initiative. We specifically thank Casey Porto and Mark Reeves (OTT/ORNL) for their continuing encouragement and support of this work. We thank the following people for help with data acquisition: D.L Beshears, G.D. Richardson and C.P. White. We would also like to thank and acknowledge C.S. Case in the preparation of this manuscript. 



\begin{abstract}
Federal and State agencies need certifiable vehicle weights for various applications, such as highway inspections, border security, check points, and port entries. ORNL weigh-in-motion (WIM) technology was previously unable to provide certifiable weights, due to natural oscillations, such as vehicle bouncing and rocking. Recent ORNL work demonstrated a novel filter to remove these oscillations. This work shows further filtering improvements to enable certifiable weight measurements (error $<0.1 \%$ ) for a higher traffic volume with less effort (elimination of redundant weighing).
\end{abstract}

\title{
1. INTRODUCTION
}

ORNL staff have developed and patented a portable system ${ }^{1-22}$ (Fig. 1) that automatically obtains the following data from a vehicle that is driven slowly ( $\leq 5 \mathrm{MPH})$ over multiple weigh-pads on smooth asphalt or concrete surfaces: (1) weight on each tire; (2) single-axle weights; (3) total vehicle weight; (4) axle spacings; (5) longitudinal and transverse centers of balance; (6) wheel spacing on each axle; (7) vehicle length, width, and height; (8) an estimate of the vehicle volume from two-dimensional digital images; (9) vehicle identification via radio-frequency ID tag or barcode; and (10) cargo characterization. This system also provides: (11) a user-friendly interface (12) elimination of human error via automated data acquisition and analysis; (13) information infrastructure for secure, real-time, wireless transmission of results; (14) 60-80\% reduction in personnel time versus in-ground scales (IGS) and wheel-weight scales, respectively; (15) 40\% decrease in the number of personnel in comparison to wheel-weight scales; (16) greater operational flexibility; (17) improved safety; and (18) lower cost. The ORNL system is much more efficient than other existing methods, as summarized in Table 1. Alternative methods use static measurement of vehicle weight, a tape measure for determining axle distances, manual recording of individual axle weights and distances, manual calculation of total vehicle weight and center of balance, and manual entry of the results into a computer system.

The ORNL WIM efficiency advantages can be truly practical, when the error (Table 2) is comparable to (or less than) In-ground Scale (IGS) error for total weight. The measure of WIM performance is percent error in weight, which is defined as,

$$
e=100(\sigma / \bar{w})
$$

Here, $\bar{w}$ is the average vehicle weight, and $\sigma$ is the sample standard deviation in the weight measurement; these quantities are explicitly defined in Section 3. 



\section{CHARACTERIZATION OF ERROR IN WEIGHT}

Weight-measurement error arises from oscillations as a vehicle traverses the WIM system. These dynamics occur, because a vehicle is (i) a multi-body system of discrete masses (e.g., body, load, wheels) that are (ii) interconnected by springs (e.g., cab-load coupling, wheel suspensions) and are (iii) excited by various aperiodic forces (e.g., uneven terrain, steering changes, acceleration, wind variability, load shifts in liquids, engine vibration) with (iv) nonlinear damping by slip-stick friction and shock absorbers. Lower-frequency oscillations $(1-5 \mathrm{~Hz})$ arise from vehicle dynamics (e.g., side-to-side rocking, front-toback rocking, vertical bouncing of the load on the suspension, load-bed flexure, twisting about coupling points, and nonlinear couplings among these modes). Higher-frequency oscillations (9-14 Hz) depend on vehicle size (e.g., tire rotation). Accurate weights require minimization of these oscillations, which WIM measurements presently reduce via a combination of: (a) minimal excitations by a smooth, flat, level approach, weighing, and exit; (b) constant, slow speed driving in a straight line; (c) several single-axle weight measurements as the vehicle crosses multiple weigh pads; and (d) continuous motion to foster dynamic friction, which reduces the slip-stick (static) friction. Further reduction of WIM error requires analysis of the time-serial weight data for removal of these vehicle oscillations.

A model for the vehicle oscillations, $x(t)$, over time, $t$, uses a second-order, ordinary differential equation:

$$
m \frac{d^{2} x}{d t^{2}}+\gamma \frac{d x}{d t}+k x=F(t)
$$

The variable $m$ is the vehicle mass; $\gamma$ is the damping coefficient; $k$ is the spring constant for the vehicle suspension; and the forcing function is:

$$
F(t)=A \cos (\omega t)
$$

The solution $^{23}$ is:

$$
x(t)=(A / G) \sin (\omega t-\delta), \text { where } \delta=A \cos (\gamma \omega / G)
$$

The resonance term is:

$$
G=\sqrt{m^{2}\left(\omega^{2}-\Omega^{2}\right)+\gamma^{2} \omega^{2}} \text { with } \Omega=\sqrt{(k / m)} .
$$

Real-world forces usually have multi-modal forcing functions of the form,

$$
F=\sum_{j} F_{j} \cos \left(\omega_{j} t+\phi_{j}\right)
$$

Each mode has a different amplitude $\left(F_{j}\right)$, frequency $\left(\omega_{j}\right)$, and phase $\left(\phi_{j}\right)$. Here, $\Sigma_{j}$ indicates summation over the various forcing modes. The net response to such multi-modal driving functions is the sum of the periodic solutions with a relative phase shift:

$$
x(t)=\sum_{j}\left(A_{j} / G_{j}\right) \sin \left(\omega_{j} t-\delta_{j}+\phi_{j}\right)
$$

If the forcing-function parameter values are available, then this approach can determine the mass from the vehicle oscillations. However, the forcing-function parameters are not known, and cannot be inferred 
from the time-serial weight data. Also, the arbitrary phase $\left(\phi_{j}\right)$ obscures the deterministic phase $\left(\delta_{j}\right)$ that can be used with the resonance factor $(G)$ to determine the mass. 


\section{ANALYSIS METHODOLOGY}

The considerations of the previous section lead to the conclusion that the vehicle oscillations must be removed empirically to reduce the WIM measurement error. Consequently, this work decomposes the time-serial WIM weight measurement, $W(t)$, into the form:

$$
W(t)=w+\sum_{j} A_{j} \sin \left(\omega_{j} t+\varphi_{j}\right) e^{\alpha_{j} t}
$$

Here, $w$ is the filtered vehicle weight that WIM seeks to measure. The $j$-th sinusoidal mode is characterized by an amplitude $\left(A_{j}\right)$, frequency $\left(\omega_{j}\right)$, and phase $\left(\varphi_{j}\right)$. The summation, $\Sigma_{j}$, is over all of the oscillatory modes. The test data have both exponential growth $\left(\alpha_{j}>0\right)$ and decay $\left(\alpha_{j}<0\right)$ of sinusoidal modes, which are modeled by the term, $e^{\alpha_{j} t}$. Re-arrangement of Eq. (8) extracts the filtered weight:

$$
w(t)=W(t)-\sum_{j} A_{j} \sin \left(\omega_{j} t+\varphi_{j}\right) e^{\alpha_{j} t}
$$

The left-hand side of Eq. (9) shows explicit time dependence in the filtered weight, $w(t)$, because the right-hand side is time dependent. Indeed, the results of Sect. 4 show that the filtered weight has residual time-variability, even after removal of many oscillatory modes. Experimental data from recent WIM tests were obtained at a sampling rate of $1,000 \mathrm{~Hz}(\Delta t=0.001$ second) as vehicles traversed the two-foot-long weigh pads. Minimal transients in the weight data occur in the central (one foot) section of the weigh pad, corresponding to a "flat-top" interval that was used for the weight-determination analysis. The flat-top region was traversed in $<200$ milliseconds, allowing acquisition of many cycles of the fast dynamics, and less than one cycle of the slow oscillations. Consequently, the values of $W(t)$ are available only at discrete time values, which are denoted by $W(t)=W(i \Delta t) \equiv W_{i}$. The corresponding discrete form for the filtered weight values are denoted by $w(t)=w(i \Delta t) \equiv w_{i}$. The discretized form of Eq. (9) then becomes:

$$
w_{i}=W_{i}-\sum_{j} A_{j} \sin \left(i \omega_{j}+\varphi_{j}\right) e^{i \beta_{j}}, \text { with } \beta_{j}=\alpha_{j} \Delta t
$$

Equations (8) - (10) are a generalized finite-Fourier decomposition ${ }^{24}$ of the vehicle oscillations for discrete frequencies, $\omega_{j}=j \pi / 2 N$, where the symbol, $N$, denotes the number of data points in the flat-top region. Very short flat-top intervals $(N<10)$ are ignored in this analysis. The average vehicle weight, $\bar{w}$, then is:

$$
\bar{w}=(1 / N) \sum_{i} w_{i}
$$

The corresponding sample standard deviation, $\sigma$, in the vehicle weight is given by:

$$
\sigma=\sqrt{\sum_{i}\left(w_{i}-\bar{w}\right)^{2} /(N-1)} .
$$

The summations in Eqs. (11) - (12) are from $i=1$ to $N$. The resultant percent error, $e$, in the vehicle weight is:

$$
e=100(\sigma / \bar{w})
$$


Eqs. (11) - (13) apply with or without the removal of any oscillation modes in Eq. (10). With these derivations, the specific analysis methodology (via MatLab ${ }^{25}$ ) can be described.

After initializations, the analysis code reads the stream of time-serial WIM data, and extracts the flat-top region of $N$ data points. This step is labeled (A) in Fig. 2. All subsequent steps are labeled sequentially in Fig. 2, and involve analysis of this same flat-top region of $N$ data points. Step (B) obtains the unfiltered WIM weight error via Eqs. (11) - (13) without any mode removal; that is with $w_{i}=W_{i}$. Subsequent steps, beginning with the loop initialization in step $(\mathrm{C})$, remove each successive oscillatory mode.

Step (D) performs a standard finite-Fourier transform ${ }^{18}$ ( $f f t$ function in MatLab) of the time serial data to estimate the mode parameters, using the following forms:

$$
\begin{aligned}
& A_{j}=\sqrt{B_{j}^{2}+C_{j}^{2}}, \\
& \varphi_{j}=\arctan \left(B_{j} / C_{j}\right) .
\end{aligned}
$$

Here, the symbols, $B_{j}$ and $C_{j}$, denote the amplitude of the unshifted cosine and sine terms, respectively:

$$
\begin{aligned}
& W(t)=B_{0} / 2+\sum_{j} B_{j} \cos (2 j \pi t / N)+C_{j} \sin (2 j \pi t / N), \\
& \omega_{j}=2 j \pi / N .
\end{aligned}
$$

The specific value for the mode frequency is the smallest value with:

$$
A_{j} \geq 0.9 \max \sqrt{B_{j}^{2}+C_{j}^{2}}
$$

Here, the maximum (max) is taken from all of the FFT amplitudes from Eq. (14), corresponding to the largest mode amplitude from the FFT. If the largest possible amplitude is always used to choose the mode frequency, then very high order frequencies can be chosen, when in fact a low-frequency mode also has a large, but non-maximal amplitude, and thus is more appropriate for removal. The above choice resolves this spurious removal of high-order modes.

Step (E) uses the mode-parameter estimates from step (D), together with a very crude guess for the mode growth $\left(\alpha_{j}=0.0001\right)$, as the starting point for a 4-parameter search over the set, $\left\{A_{j}, \omega_{j}, \varphi_{j}, \alpha_{j}\right\}$, to minimize the error for removal of the $j$-th (single) mode. The specific MatLab function is fminsearch. If the value of optimal frequency is within $10 \%$ of the estimate from step $(\mathrm{C})$, then the parameter values are acceptable, and are used as for the next step (F). If the optimal frequency is outside this $10 \%$ limit, then the search is repeated with the original estimates of $A_{j}$ and $\omega_{j}$, from Eqs. (14) and (17), respectively, but with a random starting point for the phase, $\varphi_{j}=2 \pi \rho$, and for the growth rate, $\alpha_{j}=0.001(2 \rho-1)$. Here, the symbol, $\rho$, denotes a uniformly-chosen random number between zero and one, via the MatLab function, rand. If twenty iterations of this random re-initialization do not find an optimal frequency within $10 \%$ of the original estimate, then the smallest-error parameter set is used for the next step.

Step (F) converts the frequency value from the previous optimization search to the nearest integer multiple of the "fundamental" frequency, $\omega_{f}=\pi / 2 N$. The value of $\omega_{f}$ is half of the value for a standard FFT, because (as explained above), the short-time sampling of the WIM weight data can only acquire less than one cycle of the slow oscillations. Other values of $\omega_{f}$ were tested, but gave poorer filtering results. If 
$\omega_{j}$ is allowed to have any (continuous) value, then two successive modes can have very close values of frequency that beat against each other, yielding non-physical results.

Step (G) uses the fixed, discrete value of $\omega_{j} \leq 2 \pi$ from step (F) and the other optimal parameters from step (E) as the starting point for a second search. This search also uses the MatLab function, fminsearch, to minimize the error over the 3-parameter search space, $\left\{A_{j}, \varphi_{j}, \alpha_{j}\right\}$. Sometimes, the search results have unphysical values (e.g., $A_{j}<0$ or with an excessive magnitude, or with $\omega_{j}<0$ ), which requires conversion of the parameter values to a "regular" form, in step $(\mathrm{H})$. In some instances, the frequency value can validly have the value, $\omega_{j}=\pi$; that is, $k=N$. In this case, the $j$-th term in Eq. (10) involves the term:

$$
A_{j} \sin \left(i \omega_{j}+\varphi_{j}\right)=A_{j} \sin \left(i \pi+\varphi_{j}\right)=A_{j} \cos (i \pi) \sin \left(\varphi_{j}\right)=A_{j}(-1)^{i} \sin \left(\varphi_{j}\right)
$$

The analysis converts both $A_{j}$ and $\varphi_{j}$, as follows:

$$
A_{j} \leftarrow A_{j} \sin \left(\varphi_{j}\right) ; \varphi_{j}=\operatorname{sign}\left[(-1)^{i}\right] .
$$

The replacement of $A_{j}$ with $A_{j} \sin \left(\varphi_{j}\right)$ avoids a large magnitude that usually occurs for $A_{j}$ in this case with $\varphi_{j}$ typically close to $\pi$. Three further sequential steps complete conversion to a regular form:

$$
\begin{aligned}
& A_{j} \leftarrow-A_{j}, \text { and } \varphi_{j} \leftarrow \varphi_{j}+\pi, \text { if } A_{j}<0, \\
& \varphi_{j} \leftarrow \varphi_{j}+2 \pi, \text { if } \varphi_{j}<0, \\
& \varphi_{j} \leftarrow \bmod _{2 \pi}\left(\varphi_{j}\right), \text { if } \varphi_{j}>2 \pi .
\end{aligned}
$$

Eq. (21a) assures $A_{j}>0$. Eq. (21b) assures $\varphi_{j}>0$. Eq. (21c) assures $0 \leq \varphi_{j} \leq 2 \pi$, by subtracting integer multiples of $2 \pi$ from $\varphi_{j}$ until the appropriate range is achieved. Eqs. (21a) - (21c) are also imbedded in step (E). If the resultant error is not lower than that for removal of the previous mode, then the search is repeated (up to 20 times) with the original fixed, discrete value of $\omega_{j}$ from step (F) and with random starting points for the amplitude, $A_{j}=2 \rho A_{j}(\mathrm{E})$, and for the phase, $\varphi_{j}=2 \pi \rho$, and for the growth/decay rate, $\alpha_{j}=0.001(2 \rho-1)$. Here, $A_{j}(\mathrm{E})$ is the optimal amplitude from step $\mathrm{E}$.

Step (I) saves the parameter values, the resultant error, and the residual weight values, $w_{i}$, after removal of the $j$-th oscillatory mode. Step (J) repeats Steps (C) - (I) to remove an additional mode with $W_{i}$ now equal to the residue after removal of the present mode. Step (J) terminates the mode-removal loop, if the resultant error is not smaller than that after removal of the previous mode. Step $(\mathrm{J})$ also terminates the mode-removal loop, when the number of modes removed, $M$, reaches floor $(N / 3)$. The MatLab function, floor, rounds a positive number down to the next smaller integer. This limit avoids over-fitting of the total number of modes that are filtered, because $N$ is the maximum number of degrees of freedom for mode removal (with the frequency values fixed at discrete values). The degrees of freedom are allocated among the 3 parameters, $\left\{A_{j}, \varphi_{j}, \alpha_{j}\right\}$, for each of the $M$ modes, implying $3 M \leq N$, yielding the above limit. Step (K) saves the results of the mode-filtering analysis, including the error for each mode removal step, the resultant parameter values, and the residual weight over time. Step (L) returns the analysis to step (A), if additional WIM data are available. Otherwise, the analysis is stopped. This algorithm is very robust, namely one that analyzes all of the datasets (Sect. 4) without user intervention.

We also comment about the repeated used of the local-search MatLab routine, fminsearch, rather than a global optimizer. First, the use of fminsearch yields excellent results, as discussed below. Second, a 
simultaneous search over all of the modes is extremely slow, and does not improve the filtered error. Consequently, we omitted a global search in favor of one-at-a-time removal of each oscillatory mode. 


\section{RESULTS FOR THE "TRAINING SET"}

The present WIM data acquisition hardware (MC12S series 8/16-bit micro-processor) was adapted to acquire time-serial data from the last wheel crossing of the last WIM weigh pad. This effort included software updates to the host computer for the data acquisition for up to ten independent, time-serial weight measurements from each of several vehicles. These data were the "training" set for development of a methodology (Sect. 3) to reduce weight variability from vehicle dynamics.

Twenty-eight (28) time-serial datasets were obtained during WIM field tests at Fort Lewis (Pierce County in the State of Washington) on October 3-6, 2006. Two military vehicles were each weighed six times: a Stryker armored vehicle (total weight $<12$ tons) and a military wrecker (total weight $>12$ tons). A civilian station-wagon-class vehicle (Suburban) was also weighed ten times without a load, and again six times with a 200-pound load. All four sets of data were analyzed as part of the methodological "training" set to provide a robust filtering algorithm to reduce the WIM measurement error.

Figure 3 shows a typical result of this analysis. Figure 3a displays the unfiltered time-serial weight data (solid line) for a military wrecker vehicle (item 12 in Table 3). The left side of Fig. 3a shows the unfiltered error $(E R R O R=0.97438 \%)$, the mean weight (MEAN=6400.879), and the number of points in the flat-top segment $(N=157)$. The raw data in this example fall erratically from a maximum to a similarly erratic minimum. The underlying trend is roughly one-half of a sine wave, which is removed via the empirical-fitting methodology of Sect. 3. The resultant best-fit curve for this first mode is shown by the dashed curve in Fig. 3a, and is typical of the time-serial dynamics for heavy vehicles. Figure $3 \mathrm{~b}$ illustrates the residual variability (solid line) after removal of the partial sine-wave of Figure 3a; the corresponding mean and percent error of the residue are at the right of the subplot, as before. The residual time-serial weight data have an erratic 2-period sine wave with a corresponding best-fit (dashed-line) curve, the removal of which leaves the residue in Fig. $3 c$ with a further error reduction. Figures $3 c-3 d$ display the residue and percent error after removal of two more oscillatory modes. Figure $3 \mathrm{e}$ shows the residual error versus time after removal of 52 modes. Table 3 shows representative parameters for the removal of each mode: amplitude $\left(A_{j}\right)$, frequency $\left(\omega_{j} / \omega_{f}\right)$, phase $\left(\varphi_{j}\right)$, growth/decay rate $\left(\alpha_{j}\right)$, and residual error $(e)$. The residual error for removal of 52 modes is $0.045 \%$, which is well below the $0.1 \%$ limit.

Table 4 summarizes the percent-error results from filtering analysis for all of the training vehicles. Table 4 shows multiple entries under the same dataset name, corresponding to several, distinct wheel crossings in the same dataset. The large unfiltered errors in the SuburbanF series of Table 3 are noteworthy, and arise from the small number of data points in the flat-top region. The average transit time was $41 \mathrm{~ms}$ to cross the central one-foot region of the weigh pad. The corresponding transit speed was 16.6 MPH, which is more than three times faster than the recommendation of $\leq 5 \mathrm{MPH}$, for which the low-error results were obtained for the Stryker and Wrecker series. Table 4 also shows the average error without and with mode filtering. The column, $e(\mathrm{u})$, presents the unfiltered error. The columns, $e(1)-e(3)$, show the error after removal of one, two, and three sinusoidal modes, respectively. The column, $e(M)$, shows the filtered error after removal of $M$ modes. The bold-face entries are the average errors for each series. For example, Stryker series has average errors of $1.355 \%, 0.227 \%, 0.214 \%, 0.201 \%$, and $0.047 \%$ for removal of zero, one, two, three, and $M$ modes, respectively. These results clearly show that high-order mode-filtering reduces the WIM error below the $0.1 \%$ level for slow-speed vehicle-weight measurements.

Figure 4 shows the percent error, $e(k)$, versus the number of filtered modes, $k \leq M$. Figure 4 a shows $e(k)$ versus $k$ for each of the Stryker-series measurements, reaching $e(k)<0.1 \%$ for $24 \leq k \leq 44$. Figure $4 \mathrm{~b}$ shows $e(k)$ versus $k$ for each of the Wrecker-series measurements, reaching $e(k)<0.1 \%$ for $17 \leq k \leq 37$. Figure $4 \mathrm{c}$ shows $e(k)$ versus $k$ for each of the Suburban-series of measurements, for which smallest error is $0.161 \%$ (item 20 of Table 4) after removal of 47 modes. Figure $4 d$ shows $e(k)$ versus $k$ for each of the 
SuburbanF-series of measurements, for which smallest error is $0.21 \%$ (item 20 of Table 4) after removal of 13 modes. These plots clearly show the consistency in mode-removal for low-error results from slow vehicles, and the greater spread (inconsistency) in mode-removal from higher-speed vehicles.

Figure 5 summarizes the results from Fig. 4 into a single plot of error versus vehicle speed. The left-most column of points (*) corresponds to the average of the Stryker-series of measurements at an average speed of $4 \mathrm{MPH}$. The second column of points from the left is the Wrecker-series of measurements at an average speed of 4.3 MPH. The second column of points from the right is the Suburban-series of measurements at 5.6 MPH. The right-most column of points shows the SuburbanF-series of measurements at an average speed of 16.6 MPH. The top curve (solid blue) is the unfiltered error for each of the vehicles with errors ranging from $0.857 \%$ (Wrecker) to $3.397 \%$ (SuburbanF). The second curve from the top (dashed red) shows the filtered error after removal of one mode with errors ranging from $0.294 \%$ (Stryker) to $2.113 \%$ (SuburbanF). The third curve from the top (chain-dashed purple) shows the filtered error after removal of two modes with errors ranging from $0.216 \%$ (Wrecker) to $1.747 \%$ (SuburbanF). The second curve from the bottom (solid green) displays the filtered error after removal of three modes with errors ranging from $0.199 \%$ (Wrecker) to $1.448 \%$ (SuburbanF). The bottom curve (dashed magenta) illustrates the filtered error after removal of all $M$ modes with error ranging from $0.048 \%$ (Wrecker) to $0.374 \%$ (SururbanF). The floor in the filtered error at $\sim 4 \mathrm{MPH}$ suggests that this speed (but probably not less) will minimize the error in WIM weight measurements. Figure 5 also shows that removal of many oscillatory modes significantly reduces the error at all speeds. 


\section{RESULTS FOR THE "TEST SET"}

A second set of WIM time-serial measurements was acquired for a realistic demonstration of the modefiltering, error reduction approach. Adequate statistics require ten (or more) independent measurements from each of several vehicles. This effort involved the following work on two WIM weigh pads: (a) addition of a 16-channel National Instruments ${ }^{\mathrm{TM}}$ data acquisition system; (b) testing and debugging of the hardware from (a); (c) software to acquire the 8-channel data from each weigh pad for each wheel crossing from (b); (d) software to convert the independent data channels from (c) into total-pad weight for each wheel crossing at each sampling time; (e) software to extract the flat-top region from (d); (f) software to provide the time-serial, total-pad weight data from both sides of the vehicle for (g) subsequent analysis by the mode-filtering algorithm from Section 3. The experimental test protocol was as follows.

1) Weigh the vehicle on a certified IGS;

2) Weigh the vehicle via the ORNL WIM system, as modified above;

3) Repeat step 2 many times for each vehicle;

4) Weigh the vehicle on a certified IGS;

5) Repeat steps 1-4 for each of several vehicles.

Steps 1 and 4 provide two identical and independent weight measurements from the IGS for each vehicle. Steps 2 and 3 provide several identical and independent weigh-in-motion measurements for the same vehicle. This protocol allows a statistical comparison of the mode-filtered WIM weights (with a corresponding standard deviation) to the IGS measurement, which is certified to a standard deviation of $<0.1 \%$ for total weight only. This protocol also allows calibration of the mode-filtered WIM weight to the certified IGS measurements. On the basis of the results in Sect. 4, all vehicles were driven slowly across the WIM weigh pad, resulting in many more data points for each wheel crossing of a pad.

Test data were obtained at ORNL's National Transportation Research Center on May 8-10, 2007. Four vehicles were weighed: Ford F-250, Freightliner truck, General Motors H3 Hummer, and Chevrolet Silverado. Weight data were obtained from two pads that simultaneously measured the left- and right-side tires as the vehicle was driven over the WIM system. Three datasets (all from the Hummer) had timeserial weight data for only one axle (two wheel crossings); the rest (125 datasets) included data from two axles (four wheel crossings for the F-250 and Silverado) or three axles (six wheel crossings for the Freightliner truck). Each vehicle was weighed in three different ways: (1) driving the vehicle normally across the weigh pads; (2) adding a $1 / 2$ " bump before crossing the weigh pads; and (3) adding a 1" bump before the weigh pads. The weight for a single weigh-pad crossing varied from 900 pounds for the Silverado to 5,500 pounds for the Freightliner truck. Table 5 characterizes the data for each vehicle, showing that the IGS variability is up to $10 / 4645$, or $0.215 \%$ (more than twice the certified error). A data quality check revealed that most of the datasets have one (or more) weight value(s) at the end of each weigh-pad crossing that are inconsistent with the other data (e.g., dramatically higher or lower than the other values). These transient points were removed before application of the mode filtering algorithm.

Tables 6-9 summarize the results in terms of the mode-filtered minimum error, $e(\min )$, in percent, and the corresponding average weight, $\bar{w}$, in pounds for each wheel crossing. These results are shown for the F250 (Table 6), the Freightliner truck (Table 7), the Hummer-H3 (Table 8), and the Silverado (Table 9). Mode-filtered error values above $0.1 \%$ are shown in bold font. Some values of $\bar{w}$ are outliers, namely different from the non-outlier, column-average, $\overline{\boldsymbol{w}}$, by more than two standard deviations. The value of $\overline{\boldsymbol{w}}$ and the corresponding standard deviation, $\sigma$, are initially determined by a column-average over all $\bar{w}$ -values. Any $\bar{w}$-value was excluded if $|\bar{w}-\overline{\boldsymbol{w}}| / \sigma>2$. The non-outlier $\underline{w}$-values were next used to obtain a new estimate of $\overline{\boldsymbol{w}}$ and $\sigma$, which were used to remove additional outlier $\bar{w}$-values by the same criterion. This process is repeated until no new outliers were identified. An underline denotes these $\bar{w}$ outliers, which occur in many cases even though the mode-filtered error is below $0.1 \%$. The total vehicle

weight, $\bar{W}$, (right-most column) in each table is the row-sum over the all wheel-weight values. The 
outlier-rejection algorithm also was applied to the total weight values. We note that the $e$ (min) value quantifies the precision of $\bar{w}$, while the value of $|\bar{w}-\overline{\boldsymbol{w}}| / \sigma$ quantifies the accuracy of $\bar{w}$. All weights are rounded to the nearest pound, because more precision is unjustified by the corresponding errors values, which are $\geq 10$ pounds. Clearly, an important subject for future work is a method to reject outlier measurements.

The two weigh pads for acquisition of this data were part of a larger 8-pad WIM system. The 6-pad WIM sub-system that did not include the two pads for recording this data flagged no problems with the data acquisition. However, the 6-pad WIM sub-system that included the two pads for recording the present data flagged many problems. One problem involved ambiguous (noisy) raw data, as denoted by an ' $\mathrm{X}$ ' in the second column of Tables 6-9. Another problem was an excessively large value of BadSpdRms, as denoted by ' $S$ ' in the second column of Tables 6-9. (See Appendix A for a detailed description of the multiple-pad WIM system, and the methodology for inferring the WIM measurements and problems.) No clear correlation exists between these flags, and the bold or underlined weight values in Tables 6-9. These problems might have arisen from noise on the additional (unshielded) wires for acquisition of the present (analog) data. Noise might have originated from concurrent experiments in nearby test cells. One solution is more careful grounding and shielding of the WIM data acquisition system in future experiments.

Further study of Tables 6-9 reveals that two columns of wheel crossings have all $e(\mathrm{~min})$ values below $0.1 \%$ (i.e., the first wheel crossing in Table 7 and the fourth wheel crossing in Table 9), while other wheel crossings from the same vehicle have many $e(\mathrm{~min})$ values above $0.1 \%$ (e.g., second, third, and sixth wheel crossings in Table 7). This result suggests that pad-level differences can influence the mode filtering. This problem needs further study, involving pad calibration, precision, and related issues.

Table 12 summaries the test results in terms of the number of error values (precision) below $0.1 \%$ from Tables 6-9. We note several important features in Table 10. First, the best results for the no-bump case are for the F-250 $(61 / 64=95 \%)$ and FreightLiner $(86 / 102=84 \%)$, which is the only heavy commercial-class vehicle ( $>15,000$ pounds) in these experiments. Second, the best results for the $1 / 2$ "'-bump case are for the Hummer $(26 / 28=93 \%)$ and the Silverado $(24 / 24=100 \%)$. The 1"-bump results show higher errors in all cases. The total rate of sub- $0.1 \%$ error is $197 / 218$ or $90 \%$. Third, the counter-intuitive decrease in error with a small bump ( $1 / 2 ")$ arises from excitation a larger, more-easily-removed oscillation, which overwhelms (and thus excludes) other less-easily-removed periodicities. However, Table 11 shows that the number of outliers (a measure of accuracy) is much lower for the non-bump cases. Consequently, the "bump" approach improves the precision (Table 10), but worsens the accuracy (Table 9) for the singlewheel-crossing data. More precise but less accurate single-wheel weights are not helpful.

Table 10 compares the WIM and IGS weights for each vehicle. The single-axle WIM weights were obtained by summing the appropriate values in Tables 6-9, rejecting the outliers, and then calculating the resultant average and standard deviation (value in parentheses) as before. The two weight values in each IGS column correspond to the pair of measurements from the above protocol. Figure 6 shows the results from Table 12 for total weights (subplot a), single axle weights (subplot b), and a combination of the total and single-axle weights (subplot c). The WIM weight is normalized by the corresponding IGS weight in each case, namely $\mathrm{Y}=($ WIM weight)/(IGS weight), with error bars of one standard deviation. A leastsquare, straight line provides an excellent fit to these data in all cases with the fitting parameters shown in each subplot. Figure 6c shows that the WIM weight measurements are systematically low by $2.6 \%$, and rise slightly $(0.03 \%$ per 1,000 pounds $)$ with increasing weight. We emphasize that only the total IGS weight is certified to an error of $<0.1 \%$, which is consistent with the WIM weight results. These results show that mode-filtering achieves a measurement error of $<0.1 \%$ in $90 \%$ of the best cases.

Some mode-filtered errors in Tables 6-9 are large; Table 8 shows the biggest errors $(0.38-0.46 \%)$ for the Hummer-BB06 dataset. Figure 7 shows the time-serial data for this case with large spikes (a rise or fall 
over a single time step). Quality analysis ${ }^{26}$ of the unfiltered data can reject such data from further analysis. However, careful study reveals that many datasets have such spikes, which are usually associated with a weight offset (also illustrated in Fig. 7), meaning that the typical weight value before the spike is different than afterward. Other datasets have large "bumps" (a rise or falls over several time steps), which are usually the first (large) oscillations in a decaying sequence. Some bumps are also associated with weight offsets, which clearly correspond to the suspension sticking in a new position after oscillation damping. Apparently, the spikes with an associated weight offset are the same phenomena in a stiff (highly damped and rapidly oscillating) suspension. We further note that the offsets for the two wheel crossings have opposite signs, corresponding to side-to-side rocking.

A novel solution to the spike-bump problem is to sum the two single-wheel datasets for each axle into a single-axle dataset, and then to mode-filter the sum as before. This approach has several advantages: (a) determination of single-axle weight (which is adequate for highway inspection stations); (b) implicit removal of side-to-side rocking; (c) reduction of the number of mode-filtered datasets by half; (d) lower mode-filtered error, as discussed below; and (e) faster computational analysis. Tables 13-16 show the results of this single-axle mode-filtering analysis. Table 13 shows that only one instance of error above $0.1 \%$ occurs for the F-250, that the values of $e(\min )$ are smaller than the single-wheel-crossing values, and that $\sigma / \overline{\boldsymbol{w}}$ is slightly lower for total weight than in Table 6 . We note that the large- and small-bump results deviate systematically from the F-250 average, although most of those weights are within two standard deviations of the average. If only the non-bump data are used for the mean and standard deviation with exclusion of outliers, then two values are excluded (\#03 and 17), as denoted by the italic weights in Table 13. Then, the non-bump F-250 total-weight average (7196 pounds) and standard deviation (39 pounds) yield $\boldsymbol{\sigma} / \overline{\boldsymbol{w}}=0.55 \%$, which is a substantial improvement over $1.9 \%$ in Table 6 , and $1.8 \%$ in Table 13. Similar single-axle improvements occur for the FreightLiner truck (Table 14), the Hummer H3 (Table 15), and the Silverado (Table 16). Table 17 shows that the single-axle error (precision) is uniformly lowest for the $1 / 2$ "-bump case. Table 18 shows that the corresponding number of outliers (a measure of accuracy) is consistently smallest for the non-bump case. More precise but less accurate single-axle weights are not helpful, so we must reject the use of $1 / 2$ "'-bump cases as less accurate. Table 19 shows the corresponding comparison of IGS and mode-filtered-WIM single-axle weights, which are not unlike the plots in Fig. 6, and hence are not shown.

A third set of WIM time-serial measurements were acquired on September 17, 2007 at ORNL's National Transportation Research Center. This experiment involved the same test protocol as the previous "test" set with in-ground scale measurements after every 3 to 7 WIM crossings (eight IGS measurements). This experiment used two 16-channel National Instruments ${ }^{\mathrm{TM}}$ data acquisition systems to acquire time-serial weights simultaneously from both the front and back axles of three vehicles (Ford F-250, Hummer H3, and Caravan) at a sampling rate of $4 \mathrm{kHz}$. On the basis of the improvements via single-axle weights, the front and back axle weight data are summed to obtain total-vehicle weight versus time, thus implicitly removing side-to-side rocking, front-to-back rocking, and vertical bouncing prior to the application of the mode filtering algorithm. However, the use of a 16-channel data acquisition system for each axle did not allow sufficiently accurate synchronization of the weight data from each axle to obtain total weight directly. Consequently, the time lag between the front and rear weight data was varied to find the minimum sample standard deviation in the total weight. Figure 7 shows an example of this deviationversus-lag plot for the Caravan-02 dataset. This plot displays no clear minimum due to a lack of timeserial synchronization in WIM data, since WinXP is not a real-time operating system in starting the two data acquisition systems. All Caravan and Hummer-H3 datasets displayed this same non-synchronization. Figure 8 shows a second example of the deviation-versus-lag for the F250-01 dataset, displaying strong maxima on either side of the clear minimum (denoted by the red star in the top plot). We focus the subsequent analysis on the twenty F-250 datasets that had such a clear minimum. Figure 8 (bottom plot) shows the resultant (unfiltered) time-serial total-weight data after summing the front- and back-axle weight data with the lag from the top subplot. Table 20 summarizes the results after application of the 
mode-filtering algorithm to these total-weight data, including the unfiltered error, $e(u)$ (second column), the filtered error, $e(\min )$ (third column), and total weight, $\underline{W}$ (right column). These results are a substantial improvement over the previous results, namely: (1) all error values, $e(\min )$, are well below $0.1 \%$ after mode removal; (2) all of the filtered-weights occur within two standard deviations of the average (no outliers); (3) total weight is consistent with the certification requirement, in contrast to single-wheel or single-axle weights as analyzed above. Consequently, the use of mode-filtering on the total weight data provides both lower error (more precise), as well as more accurate (no outlier) values. 


\section{DISCUSSION}

Error reduction below $0.1 \%$ via mode filtering results in essentially no further change in the WIM weight. Consequently, a substantial speed improvement in the mode-filtering algorithm is possible by termination of the analysis, when the error reaches this limit. The residual weight variability after completion of the mode filtering has a complex waveform (e.g., Figure 3e) that is reminiscent of nonlinear time-serial data from other analyses ${ }^{27}$. The use of an explicitly nonlinear, statistical approach for WIM error reduction may therefore be useful. These ideas provide avenues for further development effort.

The achievement of sub-0.1\%-error in the WIM system enables further technology development, on which we comment next. First, this error level corresponds to $<6$ pounds in a 6,000-pound wheel weight for heavy vehicles. The weigh-pad calibration error is presently \pm 50 pounds for $\leq 5,000$ pounds and \pm 100 pounds for 5,000 - 17,000 pounds. Consequently, improvement in WIM accuracy will require better calibration, and/or more accurate sensors (presently stain-gauge based). Second, further reduction in WIM error also requires improvement in the present 12-bit analog-to-digital (A-to-D) conversion, which corresponds to one part in $2^{12}=4,096$ or $\sim 1.5$ pounds in a 6,000-pound wheel weight. Commercial data acquisition systems can now provide 16-bit A-to-D conversion or $6000 / 2^{16} \sim 0.1$ pound, which is more than adequate. Third, this same error level is desirable at higher vehicle speeds, for which a longer weighpad length is appropriate. Specifically, a vehicle tire crosses the central one-foot of the present WIM weigh pad in 170 milliseconds at $4 \mathrm{MPH}$, corresponding to acquisition of 170 data points in the flat-top region at a sampling rate of $1,000 \mathrm{~Hz}$. The larger error for the Suburban vehicle (Table 1) occurred, because the higher vehicle speed (>15 MPH) restricted the data acquisition to far fewer data points for the error reduction analysis. Consequently, a longer weigh-pad length (e.g., 3 feet long, depending on a cost-benefit analysis) would provide a 2-foot central region for adequate data at $10 \mathrm{MPH}$. (We also note that the Suburban-vehicle weight results are not typical of heavy commercial vehicles, for which the WIM system is intended.) All of these further improvements involve straight-forward development paths, and would substantially enhance the commercial use of the WIM measurement system in collaboration with an industrial partner. These ideas for development will substantially enhance the WIM technology. 



\section{CONCLUSIONS}

Over the last decade, ORNL staff have developed and patented a substantial portfolio of intellectual property (IP) for the WIM technology $y^{1-8}$. The present work provides an additional and significant improvement to the WIM technology and the corresponding intellectual property ${ }^{9}$. Namely, this work demonstrates a mode filter that reduces the error in WIM weight measurements to $<0.1 \%$. This error is comparable to that from certified IGS scales. Thus, the ORNL WIM technology has the efficiency and safety advantages of a weigh-in-motion system, together with an error level comparable to IGS. This report formally documents the WIM error-reduction work, including intellectual property improvements.

The second specific benefit of this reduction of WIM weight-measurement error is increased interest in commercialization of this ORNL IP. We have identified two interested parties, with whom we have discussed licensing of the technology. ORNL staff will continue to work with ORNL's Office of Technology Transfer (OTT) to interest such potential partners in the technology.

The third benefit of this advancement is a commercializable prototype with both lower measurement error and greater efficiency than competing technologies, as discussed in the Introduction. Certification of the WIM technology for $<0.1 \%$ error requires many additional measurements (many hundreds to thousands) to provide a solid statistical basis. The present work provides a clear path to certification. 



\section{REFERENCES}

${ }^{1}$ J. D. Muhs, M. B. Scudiere, and J. K. Jordan, "Method and apparatus for converting static in-ground vehicle scales into weigh-in-motion systems," US Patent \#6,459,050 (October 1, 2002).

${ }^{2}$ D. L. Beshears, G. J. Capps, J. K. Jordan, J. V. LaForge, J. D. Muhs, R. N. Nodine, M. B. Scudiere, and C. P. White, "System and methods for accurately weighing and characterizing moving vehicles,” US Patent \#5,998,741 (December 7, 1999).

${ }^{3}$ D. L. Beshears, G. J. Capps, J. K. Jordan, J. V. LaForge, J. D. Muhs, R. N. Nodine, M. B. Scudiere, and C. P. White, "System and method for accurately weighing and characterizing moving vehicles," US Patent \#5,959,259 (September 28, 1999).

${ }^{4}$ J. D. Muhs, J. K. Jordan, K. W. Tobin, and J. V. LaForge, "Apparatus for weighing and identifying characteristics of a moving vehicle," US Patent \#5,260,520 (November 9, 1993).

${ }^{5}$ D. L. Beshears, S. G. Batsell, R. K. Abercrombie, M. B. Scudiere, and C. P. White, "System and method for identifying, validating, weighing and characterizing moving or stationary vehicles and cargo," US Patent \#7,305,324 B2 (December 4, 2007).

${ }^{6}$ D. L. Beshears, M. B. Scudiere, and C. P. White, "System and method for weighing and characterizing moving or stationary vehicles and cargo," Divisional US Patent Application \#11/550,482 (October 18, 2006).

${ }^{7}$ R. K. Abercrombie and B. G. Schlicher, "Method and System for Determining a Volume of an Object from Two-Dimensional Images," US Patent Application \#11/583,473 (October 18, 2006).

8 "Geo-registration of Images/Videoframes Using Mulitple Data Sources Including Telemetry, Georegistered Elevation and Image Data, Pattern and Feature Recognition," Patent IDEA 05-127.

${ }^{9}$ L. M. Hively and R. K. Abercrombie, "Reducing Errors in Vehicle Weighing Systems," Provisional US Patent Application \#61/003,095 (November 14, 2007).

${ }^{10}$ R. M. Walker, R. K. Abercrombie, and S. G. Batsell, "Performance Based Commercial Vehicle Inspection System," US Patent Application \#11/703,992 (February 8, 2007).

${ }^{11}$ K. W. Tobin, and J. D. Muhs, "Algorithm for a novel fiber-optic weigh-in-motion sensor system," ORNL/TM-2003/538 (Oak Ridge National Laboratory, Oak Ridge, TN) 2003.

${ }^{12}$ R. K. Abercrombie, J. E. Coats, Jr., and R. B. Honea, "Weigh-In-Motion (WIM) Technology for InTheater Applications," 83rd Annual Meeting of Transportation Research Board, Washington, DC USA, January 14, 2004.

13 J. E. Coats, Jr., R. K. Abercrombie, D. L. Beshears, and R. B. Honea, "Weigh-In-Motion Technology for Military Operations: Developing a Portable, Safe, and Accurate System," TR News - Transportation Research Board of the National Academies, vol.231, March-April 2004 pp.16-18.

${ }^{14}$ R. K. Abercrombie, F. T. Sheldon, B. G. Schlicher, and K. M. Daley, "Development of the Joint Weigh-In-Motion and Measurement Reach Back Capability - The Configuration and Data Management Tool for Validation, Verification, Testing and Certification Activities," Logistics Spectrum, Volume 38, Issue 4, 2004, p. 4-9, (published December 2005).

${ }^{15}$ R. K. Abercrombie, "Weigh-in-Motion (WIM) Research and Development Activities at ORNL," $4^{\text {th }}$ International Conference on Weigh-in-Motion, Taipei, Taiwan, February 21, 2005. 
${ }^{16}$ R. K. Abercrombie, D. L. Beshears, M. B. Scudiere, J. E. Coats, Jr., F. T. Sheldon, C. Brumbaugh, E. Hart, and R. McKay, "Weigh-In-Motion Research and Development Activities at the Oak Ridge National Laboratory," Proceeding of 4h International Conference on Weigh In Motion, Taipei, Taiwan, National Science Council, National Taiwan University Publications (ISBN 986-00-0417-X), 2005 pp.139-149.

${ }^{17}$ R. K. Abercrombie, "Next Generation Weigh-In-Motion: Enhancing Weighing and Measuring of Military Vehicles/Cargo," Institute for Defense and Government Advancement 3rd Annual Meeting, Arlington, VA USA, March 1, 2005.

${ }^{18}$ R. K. Abercrombie, F. T. Sheldon, B. G. Schlicher, and K. M. Daley, "Development of the Joint Weigh-In-Motion and Measurement Reach Back Capability," 40th Annual International Logistics Conference 2005, Logistics: Product and Process for Capacity, Orlando, Florida August 16, 2005.

19 "Weigh-In-Motion Generation II," U.S. Army Deployment Process Modernization Office (DPMO) Quarterly Army Division Transportation Officer (DTO) \& Mobility Officer (MO) Newsletter, Volume 1, Issue 1, p.5, May 20, 2005.

${ }^{20}$ R. K. Abercrombie. F. T. Sheldon, and B. G. Schlicher, "WIM Configuration and Data Management Activities," in North American Travel Monitoring Exhibition \& Conference, Minneapolis, Minnesota, June 4-7, 2006.

21 "Technologies for Troops: Getting There Faster" in ORNL Review, Volume 39, November 1, 2006, http://www.ornl.gov/info/ornlreview/v39 1 06/article08.shtml, (Last accessed January 30, 2008).

22 R. K. Abercrombie, D. L. Beshears, L. M. Hively, M. B. Scudiere, F. T. Sheldon, J. L. Schmidhammer, J. Vanvactor, ORNL/TM-2005/164, "Prototype Weigh-In-Motion Performance", October 2006.

${ }^{23}$ D. Halliday and R. Resnick, Physics Parts I \& II, John Wiley and Sons publ. (1966) pp.372-375.

${ }^{24}$ S.M. Selby and B. Girling, Standard Mathematical Tables, Chemical Rubber Company publ. (1965) pp. 410-413.

${ }^{25}$ See http://www.mathworks.com for details (Last accessed January 30, 2008).

${ }^{26}$ L.M. Hively and E.G. Ng, "Integrated Method for Chaotic Time Series Analysis," U.S. Patent \#5,815,413 (September 29. 1998).

${ }^{27}$ V. Protopopescu and L.M. Hively, "Phase-space Dissimilarity Measures of Nonlinear Dynamics: Industrial and Biomedical Applications," Recent Res. Devel. Physics, 6 (2005) 649-688. 
Appendix A

TABLES AND FIGURES 



\section{APPENDIX A. TABLES AND FIGURES}

Table 1. Time and motion study results

\begin{tabular}{|c|c|c|c|c|}
\hline Weighing/Measuring Techniques & $\begin{array}{c}\text { Min:Sec (with } \\
\text { marking) }\end{array}$ & $\begin{array}{c}\text { Min:Sec } \\
\text { (no marking) }\end{array}$ & $\begin{array}{c}\text { Personnel } \\
\text { Required }\end{array}$ & $\begin{array}{c}\text { \% of Data With } \\
\text { Human Errors }\end{array}$ \\
\hline Static Scale/Tape Measure & $7: 38$ & $4: 48$ & 3 & $9 \%$ \\
\hline Wheel-Weight Scales/Tape Measure & $7: 46$ & $4: 52$ & 7 & $14 \%$ \\
\hline ORNL System & $3: 03$ & $0: 13$ & 3 & none found \\
\hline
\end{tabular}

Table 2. Percent error (16 vehicle configurations between 5,600 and 70,000 pounds)

\begin{tabular}{|l|c|c|}
\hline Scale Type & $\boldsymbol{e}$ (total weight) & $\boldsymbol{e}$ (axle weight) \\
\hline ORNL weigh in motion & 0.62 & 1.12 \\
\hline In-ground, static scale & 0.10 & 1.06 \\
\hline Portable, wheel-weight scales & 0.36 & 0.51 \\
\hline
\end{tabular}


Table 3. Mode parameters for wrecker 6 analysis (item 12 of table 2)

\begin{tabular}{|c|c|c|c|c|c|}
\hline Mode \# & $A_{j}$ & $\omega_{j} / \omega_{f}$ & $\varphi_{j}$ & $\alpha_{j}$ & $e(\%)$ \\
\hline 1 & 95.2472 & 1 & 1.3313 & -0.0012 & 0.2462 \\
\hline 2 & 8.2832 & 4 & 5.0593 & 0.0045 & 0.2025 \\
\hline 3 & 11.4213 & 8 & 1.0561 & -0.0059 & 0.1830 \\
\hline 4 & 3.7675 & 20 & 0.0386 & 0.0030 & 0.1749 \\
\hline 5 & 0.7999 & 2 & 2.3204 & 0.0131 & 0.1708 \\
\hline 6 & 3.4096 & 10 & 4.0906 & -0.0010 & 0.1671 \\
\hline 7 & 3.0701 & 14 & 4.9012 & -0.0001 & 0.1637 \\
\hline 8 & 0.6711 & 27 & 6.0528 & 0.0144 & 0.1602 \\
\hline 9 & 7.2189 & 37 & 1.4365 & -0.0191 & 0.1569 \\
\hline 10 & 2.8293 & 48 & 2.7994 & 0.0013 & 0.1529 \\
\hline 11 & 2.3573 & 52 & 2.4696 & 0.0042 & 0.1482 \\
\hline 12 & 2.3815 & 76 & 0.9351 & 0.0029 & 0.1442 \\
\hline 13 & 2.3125 & 96 & 1.2766 & 0.0025 & 0.1407 \\
\hline 14 & 1.3846 & 88 & 5.0775 & 0.0090 & 0.1358 \\
\hline 15 & 2.2760 & 140 & 3.4244 & 0.0043 & 0.1306 \\
\hline 16 & 3.7129 & 45 & 1.8259 & -0.0032 & 0.1265 \\
\hline 17 & 1.9396 & 109 & 0.9431 & 0.0034 & 0.1232 \\
\hline 18 & 2.6694 & 125 & 0.4254 & -0.0007 & 0.1199 \\
\hline 19 & 2.5489 & 114 & 6.2634 & -0.0019 & 0.1174 \\
\hline 20 & 1.6380 & 130 & 3.7027 & -0.0011 & 0.1162 \\
\hline 21 & 4.0992 & 147 & 2.7709 & -0.0038 & 0.1108 \\
\hline 22 & 1.3923 & 18 & 2.1252 & 0.0053 & 0.1079 \\
\hline 23 & 1.2566 & 40 & 2.5187 & 0.0060 & 0.1052 \\
\hline 24 & 2.0693 & 59 & 0.3155 & 0.0015 & 0.1019 \\
\hline 25 & 4.9993 & 71 & 4.1603 & -0.0191 & 0.0994 \\
\hline 26 & 1.0477 & 69 & 4.2485 & 0.0010 & 0.0986 \\
\hline 27 & 2.5581 & 66 & 0.9991 & -0.0028 & 0.0959 \\
\hline 28 & 1.5289 & 84 & 2.9550 & 0.0002 & 0.0943 \\
\hline 29 & 0.8959 & 80 & 4.8833 & 0.0093 & 0.0910 \\
\hline 30 & 0.8574 & 99 & 0.2253 & 0.0051 & 0.0898 \\
\hline 31 & 1.5192 & 93 & 6.2437 & 0.0050 & 0.0859 \\
\hline 32 & 2.6482 & 25 & 2.4241 & -0.0043 & 0.0831 \\
\hline 33 & 1.0965 & 126 & 1.2292 & -0.0107 & 0.0828 \\
\hline 34 & 2.1482 & 122 & 5.4300 & 0.0005 & 0.0790 \\
\hline 35 & 1.3610 & 50 & 0.0882 & 0.0024 & 0.0768 \\
\hline 36 & 4.7227 & 156 & 0.3636 & -0.0097 & 0.0734 \\
\hline 37 & 0.5681 & 5 & 3.9061 & 0.0112 & 0.0711 \\
\hline 38 & 1.5955 & 16 & 5.9471 & -0.0003 & 0.0690 \\
\hline 39 & 0.3049 & 33 & 2.6040 & 0.0160 & 0.0663 \\
\hline 40 & 0.8304 & 54 & 0.0677 & 0.0067 & 0.0641 \\
\hline 41 & 2.5939 & 63 & 4.9764 & -0.0064 & 0.0613 \\
\hline 42 & 4.2213 & 90 & 5.7000 & -0.0169 & 0.0579 \\
\hline 43 & 0.6118 & 137 & 4.1081 & 0.0095 & 0.0552 \\
\hline 44 & 1.4269 & 160 & 6.0996 & 0.0004 & 0.0527 \\
\hline 45 & 1.0490 & 12 & 1.8679 & -0.0012 & 0.0516 \\
\hline 46 & 0.3870 & 22 & 1.4481 & 0.0103 & 0.0502 \\
\hline 47 & 1.1237 & 82 & 0.7753 & -0.0014 & 0.0489 \\
\hline 48 & 0.8899 & 85 & 2.8206 & -0.0087 & 0.0486 \\
\hline 49 & 0.1512 & 95 & 2.7723 & 0.0132 & 0.0482 \\
\hline 50 & 0.1643 & 83 & 5.9309 & 0.0049 & 0.0481 \\
\hline 51 & 1.0832 & 77 & 4.3522 & 0.0016 & 0.0461 \\
\hline 52 & 0.0857 & 107 & 3.5684 & 0.0191 & 0.0454 \\
\hline
\end{tabular}


Table 4. Unfiltered error, e(u), and filtered error, e(n), in training sets

\begin{tabular}{|l|l|l|l|l|l|l|l|}
\hline Dataset & $N$ & $e(\mathrm{u})$ & $e(1)$ & $e(2)$ & $e(3)$ & $e(M)$ & $M$ \\
\hline 1) StrykerA421 & 185 & 1.895 & 0.367 & 0.281 & 0.270 & 0.076 & 61 \\
\hline 2) StrykerA422 & 179 & 0.519 & 0.251 & 0.211 & 0.201 & 0.048 & 59 \\
\hline 3) StrykerA423 & 121 & 1.470 & 0.255 & 0.240 & 0.229 & 0.055 & 40 \\
\hline 4) StrykerA424 & 189 & 1.926 & 0.309 & 0.264 & 0.245 & 0.047 & 63 \\
\hline 5) StrykerA425 & 181 & 1.531 & 0.356 & 0.259 & 0.253 & 0.052 & 60 \\
\hline 6) StrykerA426 & 174 & 0.786 & 0.227 & 0.214 & 0.211 & 0.052 & 58 \\
\hline average & $\mathbf{1 7 2}$ & $\mathbf{1 . 3 5 5}$ & $\mathbf{0 . 2 9 4}$ & $\mathbf{0 . 2 4 5}$ & $\mathbf{0 . 2 3 5}$ & $\mathbf{0 . 0 5 5}$ & \\
\hline 7) Wrecker1 & 157 & 1.604 & 0.268 & 0.233 & 0.221 & 0.054 & 52 \\
\hline 8) Wrecker2 & 157 & 0.966 & 0.370 & 0.214 & 0.182 & 0.037 & 52 \\
\hline 9) Wrecker3 & 157 & 0.740 & 0.474 & 0.213 & 0.197 & 0.056 & 52 \\
\hline 10) Wrecker4 & 157 & 0.320 & 0.253 & 0.224 & 0.210 & 0.045 & 52 \\
\hline 11) Wrecker5 & 156 & 0.540 & 0.365 & 0.212 & 0.204 & 0.058 & 52 \\
\hline 12) Wrecker6 & 157 & 0.974 & 0.246 & 0.203 & 0.183 & 0.039 & 52 \\
\hline average & $\mathbf{1 5 7}$ & $\mathbf{0 . 8 5 7}$ & $\mathbf{0 . 3 3 4}$ & $\mathbf{0 . 2 1 6}$ & $\mathbf{0 . 1 9 9}$ & $\mathbf{0 . 0 4 8}$ & \\
\hline 13 Suburban1 & 90 & 1.512 & 0.827 & 0.789 & 0.737 & 0.221 & 30 \\
\hline 14) & 89 & 1.470 & 0.980 & 0.951 & 0.913 & 0.228 & 29 \\
\hline 15) & 151 & 1.608 & 1.238 & 1.158 & 1.045 & 0.233 & 50 \\
\hline 16) Suburban2 & 87 & 1.185 & 0.851 & 0.761 & 0.715 & 0.169 & 29 \\
\hline 17) & 91 & 1.093 & 0.952 & 0.866 & 0.834 & 0.188 & 30 \\
\hline 18) & 137 & 1.097 & 0.840 & 0.820 & 0.802 & 0.203 & 45 \\
\hline 19) Suburban3 & 139 & 1.331 & 0.909 & 0.877 & 0.839 & 0.208 & 46 \\
\hline 20) Suburban4 & 141 & 0.835 & 0.695 & 0.671 & 0.651 & 0.161 & 47 \\
\hline 21) Suburban5 & 145 & 1.185 & 1.010 & 0.938 & 0.914 & 0.236 & 48 \\
\hline 22) Suburban6 & 145 & 1.428 & 1.198 & 1.035 & 0.945 & 0.268 & 48 \\
\hline average & $\mathbf{1 2 2}$ & $\mathbf{1 . 2 7 4}$ & $\mathbf{0 . 9 5 0}$ & $\mathbf{0 . 8 8 7}$ & $\mathbf{0 . 8 4 0}$ & $\mathbf{0 . 2 1 1}$ & \\
\hline 23) SuburbanF1 & 42 & 1.793 & 1.456 & 1.236 & 1.129 & 0.210 & 13 \\
\hline 24) SuburbanF2 & 40 & 3.436 & 1.770 & 1.477 & 1.321 & 0.411 & 13 \\
\hline 25) SuburbanF3 & 41 & 5.787 & 3.191 & 2.858 & 1.991 & 0.592 & 13 \\
\hline 26) SuburbanF4 & 45 & 2.292 & 1.576 & 1.422 & 1.088 & 0.235 & 15 \\
\hline 27) SuburbanF5 & 37 & 5.400 & 3.406 & 2.420 & 2.243 & 0.582 & 12 \\
\hline 28) SuburbanF6 & 43 & 1.673 & 1.281 & 1.068 & 0.912 & 0.216 & 14 \\
\hline average & $\mathbf{4 1}$ & $\mathbf{3 . 3 9 7}$ & $\mathbf{2 . 1 1 3}$ & $\mathbf{1 . 7 4 7}$ & $\mathbf{1 . 4 4 8}$ & $\mathbf{0 . 3 7 4}$ & \\
\hline & & & & & & & \\
\hline
\end{tabular}

Table 5. Characterization of test datasets

\begin{tabular}{|c|c|c|c|c|c|c|c|c|}
\hline \multirow[b]{2}{*}{ Vehicle } & \multicolumn{4}{|c|}{ In-Ground Scale Weight (lbs) } & \multicolumn{4}{|c|}{ Number of Data Sets } \\
\hline & axle 1 & axle 2 & axle 3 & total & Normal & $1 / 2 "$ Bump & 1" Bump & Total \\
\hline F-250 & $\begin{array}{l}4,520 \\
4,490\end{array}$ & $\begin{array}{l}2,890 \\
2,910\end{array}$ & & $\begin{array}{l}7,410 \\
7,400\end{array}$ & 16 & 5 & 6 & 27 \\
\hline Freightliner & $\begin{array}{l}11,040 \\
10,960\end{array}$ & $\begin{array}{l}4,300 \\
4,350\end{array}$ & $\begin{array}{l}3,900 \\
3,930\end{array}$ & $\begin{array}{l}19,240 \\
19,240\end{array}$ & 17 & 6 & 9 & 32 \\
\hline Hummer & $\begin{array}{r}2,520 \\
2,510\end{array}$ & $\begin{array}{l}2,440 \\
2,450\end{array}$ & & $\begin{array}{r}4,960 \\
4,960\end{array}$ & 18 & 7 & 11 & 36 \\
\hline Silverado & $\begin{array}{l}2,780 \\
2,770\end{array}$ & $\begin{array}{l}1,870 \\
1,870\end{array}$ & & $\begin{array}{l}4,650 \\
4,640 \\
\end{array}$ & 18 & 6 & 9 & 33 \\
\hline Total Sets & & & & & 69 & 24 & 35 & 128 \\
\hline
\end{tabular}


Table 6. Mode-removal results for each wheel crossing of F-250 vehicle

\begin{tabular}{|c|c|c|c|c|c|c|c|c|c|c|}
\hline \multirow[t]{2}{*}{ Set \# } & & \multicolumn{2}{|c|}{$\begin{array}{l}1^{\text {st }} \text { wheel } \\
\text { crossing }\end{array}$} & \multicolumn{2}{|c|}{$\begin{array}{l}2^{\text {nd }} \text { wheel } \\
\text { crossing }\end{array}$} & \multicolumn{2}{|c|}{$\begin{array}{l}3^{\text {rd }} \text { wheel } \\
\text { crossing }\end{array}$} & \multicolumn{2}{|c|}{$\begin{array}{l}4^{\text {th }} \text { wheel } \\
\text { crossing }\end{array}$} & \multirow{2}{*}{$\frac{\text { Total }}{\bar{W}}$} \\
\hline & Flags & $e(\min )$ & $\bar{W}$ & $e(\min )$ & $\bar{W}$ & $e(\min )$ & $\bar{w}$ & $e(\min )$ & $\bar{W}$ & \\
\hline 01 & $\mathrm{X}$ & 0.0673 & 2098 & 0.1213 & 1373 & 0.0442 & 2308 & 0.0616 & 1497 & 7276 \\
\hline 02 & X & 0.0412 & 2153 & 0.0661 & 1336 & 0.0388 & 2245 & 0.0501 & 1477 & 7211 \\
\hline 03 & & 0.0493 & 2130 & 0.0464 & 1356 & 0.0351 & 2298 & 0.0468 & 1501 & 7285 \\
\hline 04 & & 0.0448 & 2128 & 0.0985 & 1372 & 0.1283 & 2275 & 0.0446 & 1493 & 7268 \\
\hline 05 & & 0.0728 & 2098 & 0.0646 & 1371 & 0.0453 & 2179 & 0.0640 & 1511 & 7159 \\
\hline 06 & & 0.0360 & 2154 & 0.0791 & 1369 & 0.0394 & 2237 & 0.0577 & 1474 & 7234 \\
\hline 07 & X & 0.0573 & 2130 & 0.0484 & 1377 & 0.0387 & 2253 & 0.0508 & 1479 & 7239 \\
\hline 08 & & 0.0416 & 2143 & 0.0624 & 1386 & 0.0599 & 2250 & 0.0679 & 1487 & 7266 \\
\hline 09 & X & 0.1270 & 2080 & 0.0586 & 1302 & 0.0333 & 2232 & 0.0594 & 1465 & 7079 \\
\hline 10 & & 0.0546 & 2064 & 0.0441 & 1361 & 0.0367 & 2291 & 0.0539 & 1497 & 7213 \\
\hline 11 & X & 0.0661 & 2085 & 0.0638 & 1350 & 0.0421 & 2248 & 0.0564 & 1512 & 7195 \\
\hline 12 & X & 0.0781 & 2118 & 0.0628 & 1385 & 0.0368 & 2247 & 0.0703 & 1499 & 7249 \\
\hline 13 & X & 0.0397 & 2085 & 0.0438 & 1380 & 0.0296 & 2252 & 0.0470 & 1505 & 7222 \\
\hline 15 & $\mathrm{~S}$ & 0.0520 & 2088 & 0.0981 & 1340 & 0.0861 & 2283 & 0.0540 & 1516 & 7227 \\
\hline 16 & $\mathrm{~S}$ & 0.0559 & 2064 & 0.0673 & 1379 & 0.0414 & 2233 & 0.0543 & 1497 & 7173 \\
\hline 17 & & 0.0358 & 2057 & 0.0773 & 1367 & 0.0776 & 2216 & 0.0513 & 1492 & 7132 \\
\hline b1 & X & 0.1333 & 2131 & 0.0734 & 1445 & 0.0348 & 2366 & 0.0533 & 1568 & 7510 \\
\hline b2 & & 0.0964 & 2167 & 0.1209 & 1401 & 0.0521 & 2364 & 0.0844 & $\underline{1583}$ & 7515 \\
\hline b3 & $\mathrm{S}$ & 0.1554 & 2159 & 0.0544 & 1411 & 0.0564 & 2265 & 0.1401 & $\underline{1571}$ & 7406 \\
\hline b4 & $\mathrm{S}$ & 0.0540 & 2099 & 0.1738 & 1412 & 0.0534 & 2370 & 0.0601 & $\overline{1576}$ & 7457 \\
\hline b5 & & 0.2039 & 2180 & 0.0596 & $\underline{1459}$ & 0.0395 & 2313 & 0.0577 & 1570 & 7522 \\
\hline B1 & X & 0.0720 & 2481 & 0.0721 & 1074 & 0.0944 & 2758 & 0.0687 & $\underline{1335}$ & 7648 \\
\hline B2 & $\mathrm{S}$ & 0.0507 & 1850 & 0.1336 & 1404 & 0.0322 & $\underline{2006}$ & 0.0379 & 1466 & $\underline{6726}$ \\
\hline B3 & & 0.0483 & $\underline{1751}$ & 0.1108 & 1313 & 0.0519 & $\overline{1988}$ & 0.0501 & 1500 & $\overline{6552}$ \\
\hline B4 & X & 0.0724 & 2301 & 0.1205 & 1395 & 0.0305 & 2379 & 0.1136 & 1472 & 7547 \\
\hline B5 & & 0.0811 & 2377 & 0.1112 & 1324 & 0.0432 & 2465 & 0.0403 & 1468 & 7634 \\
\hline B6 & $X$ & 0.0381 & 2127 & 0.0538 & 1379 & 0.0384 & 2180 & 0.0456 & 1482 & 7168 \\
\hline$\overline{\boldsymbol{w}}$ & & 0.0713 & 2115 & 0.0810 & 1376 & 0.0496 & 2273 & 0.0608 & 1490 & 7285 \\
\hline$\sigma / \bar{w}$ & & & 0.017 & & 0.015 & & 0.025 & & 0.011 & 0.019 \\
\hline
\end{tabular}


Table 7. Mode-removal results for each wheel crossing of freightliner truck

\begin{tabular}{|c|c|c|c|c|c|c|c|c|c|c|c|c|c|c|}
\hline \multirow[t]{2}{*}{ Set \# } & & \multicolumn{2}{|c|}{$\begin{array}{l}1^{\text {st }} \text { wheel } \\
\text { crossing }\end{array}$} & \multicolumn{2}{|c|}{$\begin{array}{l}2^{\text {nd }} \text { wheel } \\
\text { crossing }\end{array}$} & \multicolumn{2}{|c|}{$\begin{array}{l}3^{\text {rd }} \text { wheel } \\
\text { crossing }\end{array}$} & \multicolumn{2}{|c|}{$\begin{array}{l}4^{\text {th }} \text { wheel } \\
\text { crossing }\end{array}$} & \multicolumn{2}{|c|}{$\begin{array}{l}5^{\text {th }} \text { wheel } \\
\text { crossing }\end{array}$} & \multicolumn{2}{|c|}{$\begin{array}{l}6^{\text {th }} \text { wheel } \\
\text { crossing }\end{array}$} & \multirow{2}{*}{$\frac{\text { Total }}{\bar{W}}$} \\
\hline & Flags & $e(\min )$ & $\bar{W}$ & $e(\min )$ & $\bar{W}$ & $e(\min )$ & $\bar{W}$ & $e(\min )$ & $\bar{W}$ & $e(\min )$ & $\bar{W}$ & $e(\min )$ & $\bar{W}$ & \\
\hline 01 & $\mathrm{X}$ & 0.0153 & 5390 & 0.0352 & 2156 & 0.1149 & 1984 & 0.0137 & 5545 & 0.0464 & 1952 & 0.0416 & 2004 & 19031 \\
\hline 02 & $\mathrm{~S}$ & 0.0490 & 5433 & 0.1027 & 2094 & 0.0554 & 1983 & 0.0163 & 5532 & 0.0395 & 1909 & 0.1235 & 1952 & 18903 \\
\hline 03 & $\mathrm{~S}$ & 0.0197 & 5229 & 0.0285 & 2117 & 0.0927 & 1977 & 0.0136 & 5410 & 0.0377 & 1951 & 0.1270 & 1959 & 18643 \\
\hline 04 & $\mathrm{~S}$ & 0.0140 & 5305 & 0.0831 & 2152 & 0.0489 & $\underline{2006}$ & 0.0138 & 5545 & 0.0404 & 1939 & 0.0761 & 2014 & 18961 \\
\hline 05 & & 0.0244 & 5297 & 0.0300 & 2161 & 0.1194 & 1975 & 0.0118 & 5539 & 0.0375 & 1888 & 0.1257 & 2021 & 18881 \\
\hline 06 & S & 0.0172 & 5261 & 0.0298 & 2142 & 0.0901 & 1981 & 0.0521 & 5554 & 0.0345 & 1897 & 0.0400 & 1950 & 18785 \\
\hline 07 & S & 0.0175 & 5409 & 0.0282 & 2191 & 0.0753 & 1970 & 0.0182 & 5507 & 0.1403 & 1892 & 0.0383 & 1906 & 18875 \\
\hline 08 & $\mathrm{~S}$ & 0.0134 & 5322 & 0.0301 & $\underline{2216}$ & 0.0355 & 1950 & 0.0127 & 5502 & 0.0410 & 1879 & 0.1191 & 2042 & 18911 \\
\hline 09 & $\mathrm{~S}$ & 0.0322 & 5328 & 0.0353 & 2170 & 0.1522 & $\underline{1929}$ & 0.0104 & 5519 & 0.0365 & 1856 & 0.0360 & 2024 & 18826 \\
\hline 10 & S & 0.0154 & 5312 & 0.0844 & 2152 & 0.0314 & $\overline{1981}$ & 0.0210 & 5454 & 0.0386 & 1881 & 0.0322 & 2012 & 18792 \\
\hline 11 & $\mathrm{~S}$ & 0.0460 & 5278 & 0.0488 & 2146 & 0.0278 & 1970 & 0.0166 & 5426 & 0.1074 & 1886 & 0.0501 & 2011 & 18717 \\
\hline 12 & S & 0.0379 & 5276 & 0.1083 & 2135 & 0.0390 & 1978 & 0.0167 & 5496 & 0.0292 & 1898 & 0.1293 & 1945 & 18728 \\
\hline 13 & $\mathrm{~S}$ & 0.0158 & 5340 & 0.0595 & 2193 & 0.0519 & 1992 & 0.0120 & 5492 & 0.0315 & 1867 & 0.0314 & 2007 & 18891 \\
\hline 14 & $\mathrm{~S}$ & 0.0371 & 5334 & 0.0321 & 2157 & 0.0346 & 1991 & 0.0478 & $\underline{5657}$ & 0.0636 & 1916 & 0.0560 & 1990 & 19045 \\
\hline 15 & & 0.0434 & 5433 & 0.0254 & 2128 & 0.0342 & 1982 & 0.0736 & $\overline{5651}$ & 0.1100 & 1901 & 0.1243 & 1930 & 19025 \\
\hline 16 & S & 0.0172 & 5349 & 0.0238 & 2141 & 0.1084 & 1984 & 0.0146 & 5471 & 0.0353 & 1915 & 0.1632 & 1922 & 18782 \\
\hline 17 & S & 0.0536 & 5335 & 0.0334 & 2124 & 0.0389 & 1978 & 0.2025 & 5575 & 0.0506 & 1943 & 0.0403 & 1930 & 18885 \\
\hline b1 & $\mathrm{S}$ & 0.0115 & 5283 & 0.0376 & 2166 & 0.0341 & 1956 & 0.0136 & 5401 & 0.0617 & 1901 & 0.1159 & 1918 & 18625 \\
\hline b2 & & 0.0427 & 5328 & 0.0385 & 2144 & 0.1105 & 1997 & 0.0985 & $\underline{5658}$ & 0.0636 & $\underline{1998}$ & 0.1378 & 1911 & 19036 \\
\hline b3 & $\mathrm{S}$ & 0.0139 & 5253 & 0.0261 & 2119 & 0.1630 & 1943 & 0.0136 & $\overline{5378}$ & 0.0284 & $\overline{1984}$ & 0.0560 & 1944 & 18621 \\
\hline b4 & $X$ & 0.0113 & $\underline{5118}$ & 0.0314 & 2118 & 0.0559 & 1959 & 0.1394 & $\underline{5713}$ & 0.0633 & 1915 & 0.1173 & 1959 & 18782 \\
\hline b5 & $\mathrm{S}$ & 0.0238 & $\overline{5165}$ & 0.0341 & 2088 & 0.0513 & 1959 & 0.0439 & $\overline{5550}$ & 0.0640 & 1965 & 0.1002 & 1917 & 18644 \\
\hline b6 & $\mathrm{S}$ & 0.0173 & $\underline{5126}$ & 0.0998 & 2105 & 0.0792 & 1961 & 0.0120 & 5494 & 0.0430 & 1926 & 0.0447 & 1954 & 18566 \\
\hline B1 & $\mathrm{S}$ & 0.0462 & 5326 & 0.0825 & $\underline{1970}$ & 0.1457 & 1943 & 0.0133 & 5432 & 0.1074 & $\underline{1690}$ & 0.1040 & 1964 & 18325 \\
\hline B2 & & 0.0699 & $\underline{5152}$ & 0.1419 & $\underline{1895}$ & 0.2471 & 1983 & 0.0249 & $\underline{5246}$ & 0.1219 & $\underline{1638}$ & 0.2095 & 1900 & 17814 \\
\hline B3 & X & 0.0191 & 5439 & 0.1622 & $\underline{1910}$ & 0.1104 & 1984 & 0.0474 & $\underline{5245}$ & 0.1881 & $\underline{1614}$ & 0.2452 & 1898 & 18090 \\
\hline B4 & S & 0.0106 & 5328 & 0.1343 & $\underline{1867}$ & 0.0961 & 1948 & 0.0107 & $\overline{5330}$ & 0.1186 & $\underline{1668}$ & 0.0875 & 1910 & 18051 \\
\hline B5 & $\mathrm{S}$ & 0.0125 & 5292 & 0.1002 & 2164 & 0.0506 & 1951 & 0.0188 & 5497 & 0.0639 & 1939 & 0.1094 & 1943 & 18786 \\
\hline B6 & $X$ & 0.0129 & 5308 & 0.1240 & 2150 & 0.1195 & 1951 & 0.0136 & 5430 & 0.0896 & 1980 & 0.1026 & 2023 & 18842 \\
\hline B7 & $\mathrm{S}$ & 0.0147 & 5358 & 0.1209 & 2097 & 0.0308 & 1973 & 0.0118 & 5472 & 0.1173 & 1945 & 0.0302 & 1965 & 18810 \\
\hline B8 & & 0.0431 & $\underline{5189}$ & 0.0801 & $\underline{2056}$ & 0.0374 & 2011 & 0.0123 & 5460 & 0.0454 & $\underline{2013}$ & 0.0367 & 1901 & 18630 \\
\hline B9 & $\mathrm{S}$ & 0.0115 & $\overline{5206}$ & 0.1056 & $\overline{2069}$ & 0.0312 & 2039 & 0.0174 & 5506 & 0.0308 & $\underline{2041}$ & 0.0581 & 1918 & 18779 \\
\hline$\overline{\boldsymbol{w}}$ & & 0.0259 & 5324 & 0.0668 & 2140 & 0.0785 & 1971 & 0.0331 & 5492 & 0.0665 & 1917 & 0.0909 & 1958 & 18814 \\
\hline$\sigma / \bar{w}$ & & & 0.011 & & 0.013 & & 0.008 & & 0.009 & & 0.018 & & 0.022 & 0.007 \\
\hline
\end{tabular}


Table 8. Mode-removal results for each wheel crossing of hummer $\mathrm{H3}$ vehicle

\begin{tabular}{|c|c|c|c|c|c|c|c|c|c|c|}
\hline \multirow[t]{2}{*}{ Set \# } & & \multicolumn{2}{|c|}{$\begin{array}{l}1^{\text {st }} \text { wheel } \\
\text { crossing }\end{array}$} & \multicolumn{2}{|c|}{$\begin{array}{l}2^{\text {nd }} \text { wheel } \\
\text { crossing }\end{array}$} & \multicolumn{2}{|c|}{$\begin{array}{l}3^{\text {rd }} \text { wheel } \\
\text { crossing }\end{array}$} & \multicolumn{2}{|c|}{$\begin{array}{l}4^{\text {th }} \text { wheel } \\
\text { crossing }\end{array}$} & \multirow{2}{*}{$\frac{\text { Total }}{\bar{W}}$} \\
\hline & Flags & $e(\min )$ & $\bar{w}$ & $e(\min )$ & $\bar{w}$ & $e(\min )$ & $\bar{W}$ & $e(\min )$ & $\bar{w}$ & \\
\hline 01 & $X$ & 0.0697 & 1153 & 0.0647 & 1162 & 0386 & 1299 & 0.0504 & 1201 & 4815 \\
\hline 02 & $\mathrm{X}$ & 0614 & 1159 & 0.0919 & 1168 & 0.0516 & 1301 & 0.0950 & 1216 & 4844 \\
\hline 03 & & 0.0726 & 1155 & 0.1162 & 1186 & 0.0517 & 1312 & 0.0907 & 1220 & 4873 \\
\hline 04 & & 0.1034 & 1159 & 0.0974 & 1190 & 0.0529 & 1277 & 0.0719 & 1189 & 4815 \\
\hline 05 & & 0.2472 & 1143 & 0.0995 & 1197 & 0.3332 & 1286 & 0.0993 & 1207 & 4833 \\
\hline 06 & X & 0.1236 & 1156 & 0.0968 & 1163 & 0.0580 & 1304 & 0.0943 & 1206 & 4829 \\
\hline 07 & $\mathrm{~S}$ & 0.1397 & 1173 & 0.1123 & 1170 & 0.0529 & 1300 & 0.0972 & 1202 & 4845 \\
\hline 08 & & 0.0976 & 1169 & 0.1180 & 1193 & -- & -- & & -- & -- \\
\hline 09 & $\mathrm{~S}$ & 0.0716 & 1148 & 0.0592 & 1173 & 0.0570 & 1271 & 0.0713 & 1207 & 4799 \\
\hline 10 & $\mathrm{~S}$ & 0.0895 & 1188 & 0.1080 & 1173 & 0.0478 & 1292 & 0.0885 & 1197 & 4850 \\
\hline 11 & & 0.0725 & $\overline{1142}$ & 0.1006 & 1174 & 0.0404 & 1291 & 0.1062 & 1206 & 4813 \\
\hline 12 & $\mathrm{~S}$ & 0.1308 & 1163 & 0.2510 & 1207 & 0.0379 & 1262 & 0.0539 & $\underline{1185}$ & 4817 \\
\hline 13 & & 0.0705 & 1176 & 0.0818 & 1180 & 0.0461 & 1299 & 0.0662 & 1197 & 4852 \\
\hline 14 & & 0.0495 & 1175 & 0.0848 & 1185 & 0.0737 & 1289 & 0.0873 & 1199 & 4848 \\
\hline 15 & $\mathrm{~S}$ & 0.1117 & 1155 & 0.1204 & 1182 & 0.0652 & 1280 & 0765 & 1213 & 4830 \\
\hline 16 & $\mathrm{~S}$ & 0.0812 & 1159 & 0.0706 & 1193 & 0.0448 & 1295 & 0.0582 & 1195 & 4842 \\
\hline 17 & $\mathrm{X}$ & 0.0842 & 1155 & 0.1144 & $\underline{1210}$ & 0.0668 & 1279 & 0.0690 & 1211 & 4855 \\
\hline 18 & $\mathrm{~S}$ & 0.0802 & 1170 & 0.0765 & $\overline{1186}$ & 0.0705 & 1311 & 0.0867 & 1228 & 4895 \\
\hline B01 & $\mathrm{S}$ & 0.1011 & 1147 & 0.0732 & 1156 & .0517 & 1282 & 0.0729 & $\overline{1162}$ & 4747 \\
\hline B02 & $\mathrm{S}$ & 0.05 & 1150 & 0.07 & 1144 & 0.0474 & 1307 & 0.0744 & $\overline{1182}$ & $\overline{4783}$ \\
\hline B0 & $\mathrm{S}$ & 0.0520 & 1149 & 0.0790 & $\overline{1134}$ & 0.0412 & 1296 & 0.0946 & $\underline{1225}$ & 4804 \\
\hline B04 & $\mathrm{S}$ & 0.0532 & 1167 & 0.0818 & $\overline{1158}$ & 0.0503 & 1276 & 0.1030 & $\overline{1189}$ & 4790 \\
\hline B05 & & 0.0443 & 1167 & 0.0475 & 1177 & 0.0440 & 1265 & 0.0608 & $\underline{1163}$ & 4772 \\
\hline B06 & & 0.0533 & 1151 & 0.0638 & $\underline{1145}$ & 0.0503 & 1272 & 0.0702 & $\underline{1176}$ & $\underline{4744}$ \\
\hline B07 & $\mathrm{S}$ & 0.0604 & 1142 & 0.0538 & $\overline{1155}$ & 0.0503 & $\underline{1245}$ & 0.0601 & $\overline{1199}$ & $\underline{4741}$ \\
\hline BB & $X$ & 0.0592 & 1165 & 0.0521 & & 0.0931 & $\overline{1273}$ & 0.1826 & 1203 & $\overline{4821}$ \\
\hline & & 0.1968 & 1136 & 4 & & 19 & 1272 & & 1220 & 4808 \\
\hline BB03 & & 0.0592 & 1172 & 0.0545 & 1190 & 0.0451 & 1272 & 0.0768 & 1216 & 4850 \\
\hline BB04 & & 0.1389 & 1144 & 0.0719 & 1164 & 0.1315 & 1390 & 0.0723 & 1209 & 4907 \\
\hline BB05 & $X$ & 0.0560 & 1149 & 0.0923 & 1165 & 0.0462 & $\overline{1318}$ & 0.0987 & 1215 & 4847 \\
\hline BB06 & & 0.3820 & 1165 & 0.4614 & 1372 & -- & -- & -- & -- & -- \\
\hline & $\mathrm{S}$ & 0.0430 & 1169 & 0.0905 & $\overline{1173}$ & 0.0551 & 1339 & 0.0800 & 1204 & 4885 \\
\hline & $\mathrm{S}$ & 0.0864 & $\underline{1183}$ & 0.0557 & 1198 & 0.0493 & $\overline{1313}$ & 0.0491 & 1208 & 4902 \\
\hline BB09 & $\mathrm{S}$ & 0.0629 & $\overline{1177}$ & 0.0492 & $\underline{1299}$ & -- & -- & -- & -- & -- \\
\hline BB10 & & 0.2846 & 1167 & 0.1329 & $\overline{1191}$ & 0.2888 & 1340 & 0.0848 & 1199 & 4897 \\
\hline BB11 & & 0.0591 & 1219 & 0.0743 & 1186 & 0.0841 & 1328 & 0.0947 & 1204 & 4937 \\
\hline$\overline{\boldsymbol{w}}$ & & 0.1002 & 1158 & 0.0983 & 1178 & 0.0718 & 1289 & 0.0827 & 1205 & 4839 \\
\hline$\sigma / \bar{w}$ & & & 0.010 & & 0.011 & & 0.012 & & 0.007 & 0.007 \\
\hline
\end{tabular}


Table 9. Mode-removal results for each wheel crossing of silverado vehicle

\begin{tabular}{|c|c|c|c|c|c|c|c|c|c|c|}
\hline \multirow[t]{2}{*}{ Set \# } & & \multicolumn{2}{|c|}{$\begin{array}{l}1^{\text {st }} \text { wheel } \\
\text { crossing }\end{array}$} & \multicolumn{2}{|c|}{$\begin{array}{l}2^{\text {nd }} \text { wheel } \\
\text { crossing }\end{array}$} & \multicolumn{2}{|c|}{$\begin{array}{l}3^{\text {rd }} \text { wheel } \\
\text { crossing }\end{array}$} & \multicolumn{2}{|c|}{$\begin{array}{l}4^{\text {th }} \text { wheel } \\
\text { crossing }\end{array}$} & \multirow{2}{*}{$\frac{\text { Total }}{\bar{W}}$} \\
\hline & Flags & $e(\min )$ & $\bar{W}$ & $e(\min )$ & $\bar{W}$ & $E(\min )$ & $\bar{W}$ & $e(\min )$ & $\bar{W}$ & \\
\hline 01 & & 0.1241 & 1310 & 0.1800 & 877 & 0.0512 & $\underline{1365}$ & 0.0575 & 937 & 4489 \\
\hline 02 & $\mathrm{~S}$ & 0.1397 & 1288 & 0.1488 & 891 & 0.0495 & 1395 & 0.0559 & 924 & 4498 \\
\hline 04 & $\mathrm{~S}$ & 0.0725 & 1280 & 0.0941 & 884 & 0.0478 & 1389 & 0.0520 & 935 & 4488 \\
\hline 05 & X & 0.0525 & 1283 & 0.0891 & 898 & 0.0388 & 1395 & 0.0508 & 930 & 4506 \\
\hline 06 & & 0.0580 & 1268 & 0.0735 & 877 & 0.0513 & 1408 & 0.0697 & 945 & 4498 \\
\hline 07 & & 0.0566 & 1272 & 0.0829 & 868 & 0.0430 & 1399 & 0.0695 & 946 & 4485 \\
\hline 08 & $\mathrm{~S}$ & 0.0791 & 1285 & 0.0772 & 889 & 0.0420 & 1403 & 0.0634 & 926 & 4503 \\
\hline 10 & X & 0.1109 & 1283 & 0.0940 & 909 & 0.0592 & 1400 & 0.0736 & 917 & 4509 \\
\hline 11 & $X$ & 0.0645 & 1289 & 0.0815 & 875 & 0.0522 & 1402 & 0.0751 & $\overline{937}$ & 4503 \\
\hline 12 & $\mathrm{~S}$ & 0.0736 & 1269 & 0.0741 & 885 & 0.0545 & 1416 & 0.0744 & 932 & 4502 \\
\hline 13 & & 0.0624 & 1316 & 0.0771 & 927 & 0.0806 & 1401 & 0.0577 & 932 & $\underline{4576}$ \\
\hline 14 & & 0.0549 & 1291 & 0.0873 & 878 & 0.0489 & 1403 & 0.0693 & 943 & 4515 \\
\hline 15 & $\mathrm{~S}$ & 0.0560 & 1293 & 0.0575 & 895 & 0.0566 & 1399 & 0.0625 & $\underline{916}$ & 4503 \\
\hline 16 & $\mathrm{~S}$ & 0.0780 & 1272 & 0.1073 & 892 & 0.0551 & 1380 & 0.0843 & $\overline{939}$ & 4483 \\
\hline 17 & $\mathrm{~S}$ & 0.1071 & 1286 & 0.0631 & 896 & 0.0496 & 1382 & 0.0584 & 935 & 4499 \\
\hline 18 & & 0.0599 & 1315 & 0.0864 & 920 & 0.0373 & 1376 & 0.0745 & $\underline{901}$ & 4512 \\
\hline 19 & $\mathrm{X}$ & 0.0580 & 1285 & 0.0717 & 894 & 0.0507 & 1397 & 0.0749 & 935 & 4511 \\
\hline 20 & $\mathrm{~S}$ & 0.0876 & 1314 & 0.0907 & 910 & 0.0391 & 1386 & 0.0579 & 924 & 4534 \\
\hline B01 & & 0.0816 & $\underline{1363}$ & 0.0888 & 922 & 0.0594 & $\underline{1470}$ & 0.0558 & 943 & $\underline{4698}$ \\
\hline B02 & & 0.0910 & $\underline{1375}$ & 0.0790 & 904 & 0.0445 & $\underline{1448}$ & 0.0597 & $\underline{956}$ & $\underline{4683}$ \\
\hline B03 & & 0.0768 & $\overline{1366}$ & 0.0627 & 900 & 0.0487 & $\overline{1461}$ & 0.0723 & $\overline{939}$ & $\overline{4666}$ \\
\hline B04 & & 0.0782 & $\underline{1363}$ & 0.0643 & 907 & 0.0435 & $\underline{1455}$ & 0.0727 & $\underline{953}$ & $\underline{4678}$ \\
\hline B05 & $\mathrm{S}$ & 0.0865 & $\underline{1354}$ & 0.0819 & 925 & 0.0489 & 1412 & 0.0861 & 923 & $\underline{4614}$ \\
\hline B06 & $X$ & 0.0935 & $\overline{1326}$ & 0.0743 & 906 & 0.0485 & $\underline{1459}$ & 0.0693 & 931 & $\underline{4622}$ \\
\hline BB01 & & 0.0645 & $\underline{1148}$ & 0.0709 & 787 & 0.0502 & $\underline{1249}$ & 0.0581 & 948 & $\underline{4132}$ \\
\hline BB02 & $\mathrm{S}$ & 0.1029 & $\underline{1121}$ & 0.0902 & $\underline{802}$ & 0.0361 & $\underline{1231}$ & 0.0693 & 931 & $\underline{4085}$ \\
\hline BB03 & $\mathrm{S}$ & 0.0648 & $\overline{1274}$ & 0.1226 & 845 & 0.0741 & $\underline{1366}$ & 0.0645 & 939 & $\underline{4424}$ \\
\hline BB04 & & 0.0438 & 1328 & 0.0801 & 919 & 0.0445 & 1412 & 0.0661 & $\underline{913}$ & $\underline{4572}$ \\
\hline BB05 & & 0.0599 & 1132 & 0.0957 & 797 & 0.0614 & 1213 & 0.0691 & 939 & 4081 \\
\hline BB06 & $X$ & 0.1008 & $\overline{1260}$ & 0.1243 & $\overline{885}$ & 0.0463 & 1327 & 0.0680 & 934 & $\underline{4406}$ \\
\hline BB07 & $\mathrm{S}$ & 0.0969 & 1304 & 0.0743 & 876 & 0.0412 & $\overline{1393}$ & 0.0544 & 934 & $\overline{4507}$ \\
\hline BB08 & & 0.1063 & 1250 & 0.0867 & 882 & 0.1086 & 1320 & 0.0687 & 934 & $\underline{4386}$ \\
\hline BB09 & & 0.0385 & 1319 & 0.0891 & 918 & 0.0375 & 1392 & 0.0562 & 913 & 4542 \\
\hline$\overline{\boldsymbol{w}}$ & & 0.0782 & 1290 & 0.0885 & 897 & 0.0515 & 1397 & 0.0658 & 935 & 4501 \\
\hline$\sigma / \bar{w}$ & & & 0.016 & & 0.019 & & 0.008 & & 0.007 & 0.002 \\
\hline
\end{tabular}


Table 10. Occurrence rate of error below $0.1 \%$ for single-wheel-crossing data

\begin{tabular}{|l|c|l|c|}
\hline Vehicle Name & Normal (\# Sets) & \multicolumn{1}{|c|}{$1 / 2$ " Bump (\# Sets) } & \multicolumn{1}{|c|}{ " Bump (\# Sets) } \\
\hline F-250 & $\mathbf{6 1 / 6 4}=\mathbf{9 5 \%}$ & $14 / 20=70 \%$ & $19 / 24=79 \%$ \\
\hline Freightliner & $\mathbf{8 6 / 1 0 2}=\mathbf{8 4} \%$ & $29 / 36=81 \%$ & $33 / 54=61 \%$ \\
\hline Hummer & $54 / 70=77 \%$ & $\mathbf{2 6} / \mathbf{2 8}=\mathbf{9 3 \%}$ & $31 / 40=78 \%$ \\
\hline Silverado & $65 / 72=90 \%$ & $\mathbf{2 4 / 2 4}=\mathbf{1 0 0} \%$ & $30 / 36=83 \%$ \\
\hline Totals & $266 / 308=86 \%$ & $\mathbf{9 3} / \mathbf{1 0 8}=\mathbf{9 1 \%}$ & $113 / 154=73 \%$ \\
\hline
\end{tabular}

Table 11. Occurrence rate of outliers for single-wheel-crossing data

\begin{tabular}{|l|c|c|c|}
\hline Vehicle Name & Normal (\# Sets) & \multicolumn{1}{|c|}{$/ 2$ " Bump (\# Sets) } & \multicolumn{1}{|c|}{ " Bump (\# Sets) } \\
\hline F-250 & $1 / 64=2 \%$ & $7 / 20=35 \%$ & $13 / 24=54 \%$ \\
\hline Freightliner & $5 / 102=5 \%$ & $7 / 36=19 \%$ & $19 / 54=35 \%$ \\
\hline Hummer & $5 / 70=7 \%$ & $9 / 28=32 \%$ & $8 / 40=20 \%$ \\
\hline Silverado & $4 / 72=6 \%$ & $12 / 24=50 \%$ & $15 / 36=42 \%$ \\
\hline Totals & $15 / 308=5 \%$ & $35 / 108=32 \%$ & $55 / 154=36 \%$ \\
\hline
\end{tabular}

Table 12. Comparison of IGS and WIM from single-wheel crossings (pounds)

\begin{tabular}{|l|c|c|c|c|c|c|c|c|}
\hline & \multicolumn{9}{|c|}{ In-Ground Scale Weight } & \multicolumn{5}{c|}{ WIM Weight } \\
\cline { 2 - 9 } Vehicle & axle 1 & axle 2 & axle 3 Total & axle 1 & axle 2 & axle 3 & Total \\
\hline F-250 & 4,520 & 2,890 & & 7,410 & 4,377 & 2,868 & & 7,285 \\
& 4,490 & 2,910 & & 7,400 & $(65)$ & $(10)$ & & $(137)$ \\
\hline Freightliner & 11,040 & 4,300 & 3,900 & 19,240 & 10,790 & 4,060 & 3,932 & 18,814 \\
& 10,960 & 4,350 & 3,930 & 19,240 & $(108)$ & $(30)$ & $(45)$ & $(136)$ \\
\hline Hummer & 2,520 & 2,440 & & 4,960 & 2,447 & 2,384 & & 4,839 \\
& 2,510 & 2,450 & & 4,960 & $(20)$ & $(15)$ & & $(36)$ \\
\hline Silverado & 2,780 & 1,870 & & 4,650 & 2,684 & 1,823 & & 4,501 \\
& 2,770 & 1,870 & & 4,640 & $(10)$ & $(9)$ & & $(10)$ \\
\hline
\end{tabular}


Table 13. Mode-removal results for each axle of F-250 vehicle

\begin{tabular}{|l|c|c|c|c|c|}
\hline \multirow{2}{*}{ Set \# } & \multicolumn{2}{|c|}{$1^{\text {st }}$ axle } & \multicolumn{2}{c|}{$2^{\text {nd }}$ axle } & Total \\
\cline { 2 - 6 } & $e(\mathrm{~min})$ & $\overline{\boldsymbol{w}}$ & $e(\mathrm{~min})$ & $\overline{\boldsymbol{W}}$ & $\bar{W}$ \\
\hline 01 & 0.0431 & 4305 & 0.0563 & 2878 & 7183 \\
02 & 0.0321 & 4398 & 0.0410 & 2823 & 7221 \\
03 & 0.0263 & 4450 & 0.0415 & 2858 & 7308 \\
04 & 0.0453 & 4389 & 0.0342 & 2844 & 7233 \\
05 & $\mathbf{0 . 1 2 5 0}$ & 4287 & 0.0402 & 2838 & 7125 \\
06 & 0.0439 & 4369 & 0.0491 & 2849 & 7218 \\
07 & 0.0321 & 4360 & 0.0271 & 2864 & 7224 \\
08 & 0.0352 & 4375 & 0.0544 & 2871 & 7246 \\
09 & 0.0280 & 4376 & 0.0507 & 2754 & 7130 \\
10 & 0.0334 & 4335 & 0.0368 & 2867 & 7202 \\
11 & 0.0255 & 4338 & 0.0417 & 2849 & 7187 \\
12 & 0.0370 & 4340 & 0.0458 & 2891 & 7231 \\
13 & 0.0284 & 4325 & 0.0352 & 2887 & 7212 \\
15 & 0.0319 & 4367 & 0.0351 & 2819 & 7186 \\
16 & 0.0248 & 4305 & 0.0431 & 2836 & 7141 \\
17 & 0.0314 & 4253 & 0.0597 & 2827 & 7080 \\
b1 & 0.0628 & 4522 & 0.0508 & 2990 & 7512 \\
b2 & 0.0922 & 4512 & 0.0552 & 2985 & 7497 \\
b3 & 0.0432 & 4429 & 0.0366 & 2976 & 7405 \\
b4 & 0.0235 & 4455 & 0.0429 & 2962 & 7417 \\
b5 & 0.0254 & 4468 & 0.0469 & 2998 & 7466 \\
B1 & 0.0908 & $\underline{5295}$ & 0.0613 & $\underline{2377}$ & $\underline{7672}$ \\
B2 & 0.0308 & $\underline{3761}$ & 0.0732 & 2875 & $\underline{6636}$ \\
B3 & 0.0241 & $\underline{3850}$ & 0.0360 & 2789 & $\underline{6639}$ \\
B4 & 0.0575 & $\underline{4732}$ & 0.0650 & 2838 & $\underline{7570}$ \\
B5 & 0.0508 & $\underline{4677}$ & 0.0452 & 2776 & 7453 \\
B6 & 0.0242 & 4249 & 0.0263 & 2894 & 7143 \\
\hline$\overline{\boldsymbol{w}}$ & 0.0425 & 4373 & 0.0456 & 2871 & 7262 \\
\hline $\boldsymbol{\sigma} / \overline{\boldsymbol{w}}$ & & 0.017 & & 0.023 & 0.018 \\
\hline
\end{tabular}


Table 14. Mode-removal results for each axle of freightliner truck

\begin{tabular}{|c|c|c|c|c|c|c|c|}
\hline \multirow[t]{2}{*}{ Set \# } & \multicolumn{2}{|c|}{$1^{\text {st }}$ axle } & \multicolumn{2}{|c|}{$2^{\text {nd }}$ axle } & \multicolumn{2}{|c|}{$3^{\text {rd }}$ axle } & \multirow{2}{*}{$\frac{\text { Total }}{\bar{W}}$} \\
\hline & $e(\min )$ & $\bar{w}$ & $e(\min )$ & $\bar{w}$ & $e(\min )$ & $\bar{w}$ & \\
\hline 01 & 0.0169 & 10984 & 0.0260 & 4064 & 0.0308 & 4010 & 19058 \\
\hline 02 & 0.0092 & 11113 & 0.0292 & 4015 & 0.0569 & $\overline{3938}$ & 19066 \\
\hline 03 & 0.0152 & $\overline{10690}$ & 0.0288 & 4027 & 0.0428 & 3910 & 18627 \\
\hline 04 & 0.0104 & 10916 & 0.0243 & 4061 & 0.1282 & $\underline{3961}$ & 18938 \\
\hline 05 & 0.0159 & 10909 & 0.0779 & 4042 & 0.1128 & $\overline{3916}$ & 18867 \\
\hline 06 & 0.0085 & 10819 & 0.0647 & 4036 & 0.0872 & 3914 & 18769 \\
\hline 07 & 0.0287 & 10907 & 0.0714 & 4083 & 0.0754 & 3927 & 18917 \\
\hline 08 & 0.0118 & 10827 & 0.0623 & 4006 & 0.0263 & 3898 & 18731 \\
\hline 09 & 0.0060 & 10813 & 0.0813 & 4016 & 0.0265 & 3885 & 18714 \\
\hline 10 & 0.0321 & 10754 & 0.0314 & 4033 & 0.0734 & 3907 & 18694 \\
\hline 11 & 0.0077 & 10709 & 0.0301 & 4087 & 0.0793 & $\underline{3949}$ & 18745 \\
\hline 12 & 0.0077 & 10788 & 0.0194 & 4038 & 0.0227 & $\overline{3904}$ & 18730 \\
\hline 13 & 0.0073 & 10811 & 0.0790 & 4049 & 0.0319 & 3930 & 18790 \\
\hline 14 & 0.0093 & 10969 & 0.0311 & 4096 & 0.0515 & 3923 & 18988 \\
\hline 15 & 0.0557 & 11062 & 0.0432 & 4039 & 0.0279 & 3914 & 19015 \\
\hline 16 & 0.0095 & $\overline{10865}$ & 0.0272 & 4061 & 0.0233 & 3904 & 18830 \\
\hline 17 & 0.0543 & 10958 & 0.0267 & 4069 & 0.0528 & 3896 & 18923 \\
\hline b1 & 0.0096 & 10839 & 0.0464 & 4068 & 0.0871 & 3866 & 18773 \\
\hline b2 & 0.0082 & 10798 & 0.0384 & $\underline{4135}$ & 0.0946 & 3922 & 18855 \\
\hline b3 & 0.0670 & 10933 & 0.0518 & $\overline{4148}$ & 0.0889 & 3874 & 18955 \\
\hline b4 & 0.0095 & 10615 & 0.0251 & $\overline{4041}$ & 0.0254 & 3879 & 18535 \\
\hline b5 & 0.0090 & 10395 & 0.0260 & 4031 & 0.0831 & 3889 & 18315 \\
\hline b6 & 0.0085 & $\overline{10518}$ & 0.0524 & 4019 & 0.0277 & 3892 & 18429 \\
\hline B1 & 0.0864 & 10655 & 0.1097 & $\underline{3664}$ & 0.0393 & 3874 & 18193 \\
\hline B2 & 0.0087 & 10570 & 0.1436 & $\overline{3467}$ & 0.0952 & 3876 & 17913 \\
\hline B3 & 0.0288 & $\underline{10533}$ & 0.0570 & $\underline{3464}$ & 0.0286 & 3877 & 17874 \\
\hline B4 & 0.0066 & $\overline{10636}$ & 0.0269 & $\underline{3498}$ & 0.0891 & 3869 & 18003 \\
\hline B5 & 0.0108 & 10719 & 0.0264 & $\overline{4096}$ & 0.0230 & 3889 & 18704 \\
\hline B6 & 0.0078 & 10831 & 0.0852 & 4067 & 0.0301 & 3881 & 18779 \\
\hline B7 & 0.0092 & 10763 & 0.0723 & $\underline{4112}$ & 0.0342 & 3880 & 18755 \\
\hline B8 & 0.0079 & 10720 & 0.0271 & $\overline{4073}$ & 0.0253 & 3854 & 18647 \\
\hline B9 & 0.0164 & 10714 & 0.1172 & 4037 & 0.0205 & 3872 & 18623 \\
\hline$\overline{\bar{w}}$ & 0.0188 & 10805 & 0.0519 & 4050 & 0.0544 & 3895 & 18809 \\
\hline$\sigma / \bar{w}$ & & 0.010 & & 0.006 & & 0.006 & 0.008 \\
\hline
\end{tabular}


Table 15. Mode-removal results for each axle of Hummer $\mathrm{H3}$ vehicle

\begin{tabular}{|c|c|c|c|c|c|}
\hline \multirow[b]{2}{*}{ Set \# } & \multicolumn{2}{|c|}{$1^{\text {st }}$ axle } & \multicolumn{2}{|c|}{$2^{\text {nd }}$ axle } & Total \\
\hline & $e(\min )$ & $\bar{w}$ & $e(\min )$ & $\bar{w}$ & $\bar{W}$ \\
\hline 01 & 0.0395 & 2453 & 0.0516 & 2379 & 4832 \\
\hline 02 & 0.0301 & 2471 & 0.0748 & 2368 & 4839 \\
\hline 03 & 0.0414 & 2473 & 0.0670 & 2418 & 4891 \\
\hline 04 & 0.0567 & 2429 & 0.0743 & 2359 & 4788 \\
\hline 05 & 0.3719 & 2426 & 0.0671 & 2425 & 4851 \\
\hline 06 & 0.0650 & 2462 & 0.0685 & $\overline{2370}$ & 4832 \\
\hline 07 & 0.0761 & 2472 & 0.0731 & 2385 & 4857 \\
\hline 08 & 0.0470 & 2396 & -- & -- & \\
\hline 09 & 0.0394 & 2421 & 0.0494 & 2347 & 4768 \\
\hline 10 & 0.0719 & 2476 & 0.0618 & 2374 & 4850 \\
\hline 11 & 0.0357 & 2440 & 0.0595 & 2381 & 4821 \\
\hline 12 & 0.1027 & 2427 & 0.0419 & 2382 & 4809 \\
\hline 13 & 0.0353 & 2488 & 0.0422 & 2408 & 4896 \\
\hline 14 & 0.1176 & 2450 & 0.0387 & 2385 & 4835 \\
\hline 15 & 0.0670 & 2441 & 0.0670 & 2400 & 4841 \\
\hline 16 & 0.0446 & 2453 & 0.0489 & 2381 & 4834 \\
\hline 17 & 0.0513 & 2438 & 0.0594 & 2418 & 4856 \\
\hline 18 & 0.1185 & 2476 & 0.0478 & 2410 & 4886 \\
\hline B01 & 0.0707 & 2451 & 0.0422 & 2317 & 4768 \\
\hline B02 & 0.0349 & 2463 & 0.0495 & 2309 & 4772 \\
\hline B03 & 0.0305 & 2423 & 0.0469 & 2359 & 4782 \\
\hline B04 & 0.0522 & 2445 & 0.0821 & 2359 & 4804 \\
\hline B05 & 0.0285 & 2405 & 0.0452 & 2355 & 4760 \\
\hline B06 & 0.0378 & 2437 & 0.0498 & $\underline{2328}$ & 4765 \\
\hline B07 & 0.0311 & 2403 & 0.0489 & 2365 & 4768 \\
\hline BB01 & 0.0329 & 2448 & 0.0591 & 2383 & 4831 \\
\hline BB02 & 0.0370 & 2416 & 0.0453 & 2397 & 4813 \\
\hline BB03 & 0.0368 & 2431 & 0.0454 & 2416 & 4847 \\
\hline BB04 & 0.1073 & 2529 & 0.0466 & 2369 & 4898 \\
\hline BB05 & 0.0275 & $\overline{2494}$ & 0.0425 & 2372 & 4866 \\
\hline BB06 & 0.4509 & 2544 & -- & -- & \\
\hline BB07 & 0.0799 & $\overline{2497}$ & 0.0482 & 2367 & 4864 \\
\hline BB08 & 0.0426 & 2506 & 0.0324 & 2399 & 4905 \\
\hline BB09 & 0.0431 & 2483 & -- & -- & \\
\hline BB10 & 0.2628 & 2515 & 0.0716 & 2396 & 4911 \\
\hline BB11 & 0.0494 & 2527 & 0.0621 & 2381 & 4908 \\
\hline$\overline{\boldsymbol{w}}$ & 0.0797 & 2450 & 0.0549 & 2382 & 4835 \\
\hline$\sigma / \bar{w}$ & & 0.012 & & 0.008 & 0.010 \\
\hline
\end{tabular}


Table 16. Mode-removal results for each axle of Silverado vehicle

\begin{tabular}{|l|c|c|c|c|c|}
\hline \multirow{2}{*}{ Set \# } & \multicolumn{2}{|c|}{$1^{\text {st }}$ axle } & \multicolumn{2}{c|}{$2^{\text {nd }}$ axle } & Total \\
\cline { 2 - 6 } & $e(\min )$ & $\bar{w}$ & $e(\min )$ & $\bar{w}$ & $\bar{W}$ \\
\hline 01 & 0.0632 & 2654 & $\mathbf{0 . 1 1 1 5}$ & 1818 & $\underline{4472}$ \\
02 & 0.0697 & 2671 & 0.0907 & 1817 & 4488 \\
04 & 0.0552 & 2674 & 0.0471 & 1811 & 4485 \\
05 & 0.0632 & 2667 & 0.0466 & 1821 & 4488 \\
06 & 0.0638 & 2655 & 0.0553 & 1835 & 4490 \\
07 & 0.0546 & 2688 & 0.0578 & 1813 & 4501 \\
08 & 0.0408 & 2687 & 0.0715 & 1811 & 4498 \\
10 & 0.0490 & 2664 & $\mathbf{0 . 1 0 0 4}$ & 1825 & 4489 \\
11 & 0.0407 & 2670 & 0.0566 & 1816 & 4486 \\
12 & 0.0400 & 2692 & 0.0496 & 1829 & $\underline{4521}$ \\
13 & 0.0406 & $\underline{2715}$ & 0.0488 & 1837 & $\underline{4552}$ \\
14 & 0.0379 & 2673 & 0.0583 & 1829 & 4502 \\
15 & 0.0360 & 2677 & 0.0458 & 1825 & 4502 \\
16 & 0.0327 & 2668 & 0.0439 & 1822 & 4490 \\
17 & 0.0603 & 2669 & 0.0509 & 1816 & 4485 \\
18 & 0.0358 & 2688 & 0.0556 & 1814 & 4502 \\
19 & 0.0365 & 2682 & 0.0479 & 1822 & 4504 \\
20 & 0.0638 & 2690 & 0.0623 & 1834 & $\underline{4524}$ \\
B01 & 0.0488 & $\underline{2831}$ & 0.0531 & $\underline{1892}$ & $\underline{4723}$ \\
B02 & 0.0471 & $\underline{2840}$ & 0.0450 & 1833 & $\underline{4673}$ \\
B03 & 0.0429 & $\underline{2827}$ & 0.0421 & 1828 & $\underline{4655}$ \\
B04 & 0.0389 & $\underline{2824}$ & 0.0564 & 1828 & $\underline{4652}$ \\
B05 & 0.0448 & $\underline{2734}$ & 0.0418 & 1824 & $\underline{4558}$ \\
B06 & 0.0361 & $\underline{2846}$ & 0.0414 & $\underline{1847}$ & $\underline{4693}$ \\
BB01 & 0.0375 & $\underline{2420}$ & 0.0365 & $\underline{1777}$ & $\underline{4197}$ \\
BB02 & 0.0355 & $\underline{2370}$ & 0.0459 & $\underline{1731}$ & $\underline{4101}$ \\
BB03 & 0.0405 & $\underline{2593}$ & 0.0626 & $\underline{1792}$ & $\underline{4385}$ \\
BB04 & 0.0278 & $\underline{2735}$ & 0.0396 & 1827 & $\underline{4562}$ \\
BB05 & 0.0601 & $\underline{2341}$ & 0.0513 & $\underline{1757}$ & $\underline{4098}$ \\
BB06 & 0.0551 & $\underline{2513}$ & 0.0575 & 1828 & $\underline{4341}$ \\
BB07 & 0.0459 & 2675 & 0.0396 & 1808 & 4483 \\
BB08 & 0.0590 & $\underline{2568}$ & 0.0489 & 1817 & $\underline{4385}$ \\
BB09 & 0.0254 & $\underline{2703}$ & 0.0571 & 1825 & $\underline{4528}$ \\
\hline$\overline{\boldsymbol{w}}$ & 0.0463 & 2675 & 0.0551 & 1823 & 4493 \\
\hline$\sigma / \overline{\boldsymbol{w}}$ & & 0.004 & & 0.004 & 0.002 \\
\hline
\end{tabular}


Table 17. Occurrence rate of error below $0.1 \%$ for single-axle data

\begin{tabular}{|l|c|l|l|}
\hline Vehicle Name & $\begin{array}{l}\text { Normal } \\
\text { (\# Sets) }\end{array}$ & $\begin{array}{l}1 / 2 \text { " Bump } \\
\text { (\# Sets) }\end{array}$ & $\begin{array}{l}1 \text { " Bump } \\
\text { (\# Sets) }\end{array}$ \\
\hline F-250 & $31 / 32=97 \%$ & $\mathbf{1 0} / \mathbf{1 0}=\mathbf{1 0 0 \%}$ & $\mathbf{1 2} / \mathbf{1 2}=\mathbf{1 0 0 \%}$ \\
\hline Freightliner & $49 / 51=96 \%$ & $\mathbf{1 8} / \mathbf{1 8}=\mathbf{1 0 0 \%}$ & $24 / 27=89 \%$ \\
\hline Hummer & $31 / 35=89 \%$ & $\mathbf{1 4} / \mathbf{1 4}=\mathbf{1 0 0 \%}$ & $17 / 20=85 \%$ \\
\hline Silverado & $34 / 36=94 \%$ & $\mathbf{1 2} / \mathbf{1 2}=\mathbf{1 0 0 \%}$ & $\mathbf{1 8} / \mathbf{1 8}=\mathbf{1 0 0} \%$ \\
\hline Totals & $145 / 154=94 \%$ & $\mathbf{5 4 / 5 4}=\mathbf{1 0 0 \%}$ & $71 / 77=92 \%$ \\
\hline
\end{tabular}

Table 18. Occurrence rate of outliers for single-axle data

\begin{tabular}{|l|c|c|c|}
\hline Vehicle Name & Normal (\# Sets) & \multicolumn{1}{|c|}{$/ 2$ " Bump (\# Sets) } & \multicolumn{1}{|c|}{ " Bump (\# Sets) } \\
\hline F-250 & $0 / 32=\mathbf{0 \%}$ & $0 / 10=\mathbf{0 \%}$ & $6 / 12=50 \%$ \\
\hline Freightliner & $5 / 51=\mathbf{1 0} \%$ & $4 / 18=22 \%$ & $7 / 27=26 \%$ \\
\hline Hummer & $1 / 35=\mathbf{7 \%}$ & $3 / 14=21 \%$ & $4 / 20=20 \%$ \\
\hline Silverado & $1 / 36=\mathbf{3 \%}$ & $8 / 12=67 \%$ & $11 / 18=61 \%$ \\
\hline Totals & $7 / 154=\mathbf{5 \%}$ & $35 / 54=32 \%$ & $55 / 77=36 \%$ \\
\hline
\end{tabular}

Table 19. Comparison of IGS and WIM for single-axle data (pounds)

\begin{tabular}{|c|c|c|c|c|c|c|c|c|}
\hline \multirow[b]{2}{*}{ Vehicle } & \multicolumn{4}{|c|}{ In-Ground Scale (IGS) Weight } & \multicolumn{4}{|c|}{ WIM Weight } \\
\hline & $\begin{array}{l}\text { axle } 1 \\
\text { nas }\end{array}$ & axle 2 & axle 3 & Total & axle 1 & axle 2 & axle 3 & Total \\
\hline $\mathrm{F}-250$ & $\begin{array}{l}4,520 \\
4,490\end{array}$ & $\begin{array}{l}2,890 \\
2,910\end{array}$ & & $\begin{array}{l}7,410 \\
7,400\end{array}$ & $\begin{array}{c}4,373 \\
(74)\end{array}$ & $\begin{array}{c}2,871 \\
(66)\end{array}$ & & $\begin{array}{l}7,262 \\
(131)\end{array}$ \\
\hline Freightliner & $\begin{array}{l}11,040 \\
10,960\end{array}$ & $\begin{array}{l}4,300 \\
4,350\end{array}$ & $\begin{array}{l}3,900 \\
3,930\end{array}$ & $\begin{array}{l}19,240 \\
19,240\end{array}$ & $\begin{array}{c}10,805 \\
(105)\end{array}$ & $\begin{array}{c}4,050 \\
(26)\end{array}$ & $\begin{array}{c}3,895 \\
(22)\end{array}$ & $\begin{array}{r}18,809 \\
(141)\end{array}$ \\
\hline Hummer & $\begin{array}{l}2,520 \\
2,510\end{array}$ & $\begin{array}{l}2,440 \\
2,450\end{array}$ & & $\begin{array}{l}4,960 \\
4,960\end{array}$ & $\begin{array}{c}2,450 \\
(29)\end{array}$ & $\begin{array}{c}2,382 \\
(19)\end{array}$ & & $\begin{array}{c}4,835 \\
(46)\end{array}$ \\
\hline Silverado & $\begin{array}{l}2,780 \\
2,770\end{array}$ & $\begin{array}{l}1,870 \\
1,870\end{array}$ & & $\begin{array}{l}4,650 \\
4,640\end{array}$ & $\begin{array}{c}2,675 \\
(11)\end{array}$ & $\begin{array}{c}1,823 \\
(9)\end{array}$ & & $\begin{array}{c}4,493 \\
(8)\end{array}$ \\
\hline
\end{tabular}


Table 20. Whole-vehicle, mode-removal results for F-250 vehicle

\begin{tabular}{|l|l|l|l|}
\hline Set \# & $e(u) \%$ & $e(\min ) \%$ & $\bar{W}$ \\
\hline 01 & 0.2199 & 0.0297 & 7098 \\
04 & 0.6109 & 0.0492 & 7174 \\
05 & 0.6580 & 0.0537 & 6935 \\
06 & 0.8496 & 0.0458 & 6915 \\
07 & 0.6226 & 0.0354 & 7107 \\
08 & 0.4773 & 0.0453 & 7117 \\
11 & 0.1439 & 0.0214 & 6973 \\
15 & 0.2426 & 0.0479 & 6935 \\
17 & 0.5013 & 0.0411 & 7195 \\
18 & 0.4303 & 0.0438 & 6927 \\
19 & 0.3411 & 0.0382 & 6987 \\
20 & 0.4404 & 0.0573 & 6820 \\
21 & 0.7406 & 0.0371 & 6909 \\
23 & 0.2528 & 0.0346 & 6990 \\
28 & 0.6265 & 0.0445 & 7074 \\
31 & 0.4022 & 0.0427 & 6881 \\
32 & 0.5088 & 0.0376 & 6865 \\
33 & 0.5655 & 0.0517 & 6881 \\
34 & 0.4377 & 0.0374 & 6879 \\
35 & 1.1327 & 0.0447 & 6809 \\
\hline mean & 0.5102 & 0.0425 & 6974 \\
\hline $\boldsymbol{\sigma} / \overline{\boldsymbol{w}}$ & & & 0.017 \\
\hline IGS & & & $7279 \pm 3$ \\
\hline
\end{tabular}




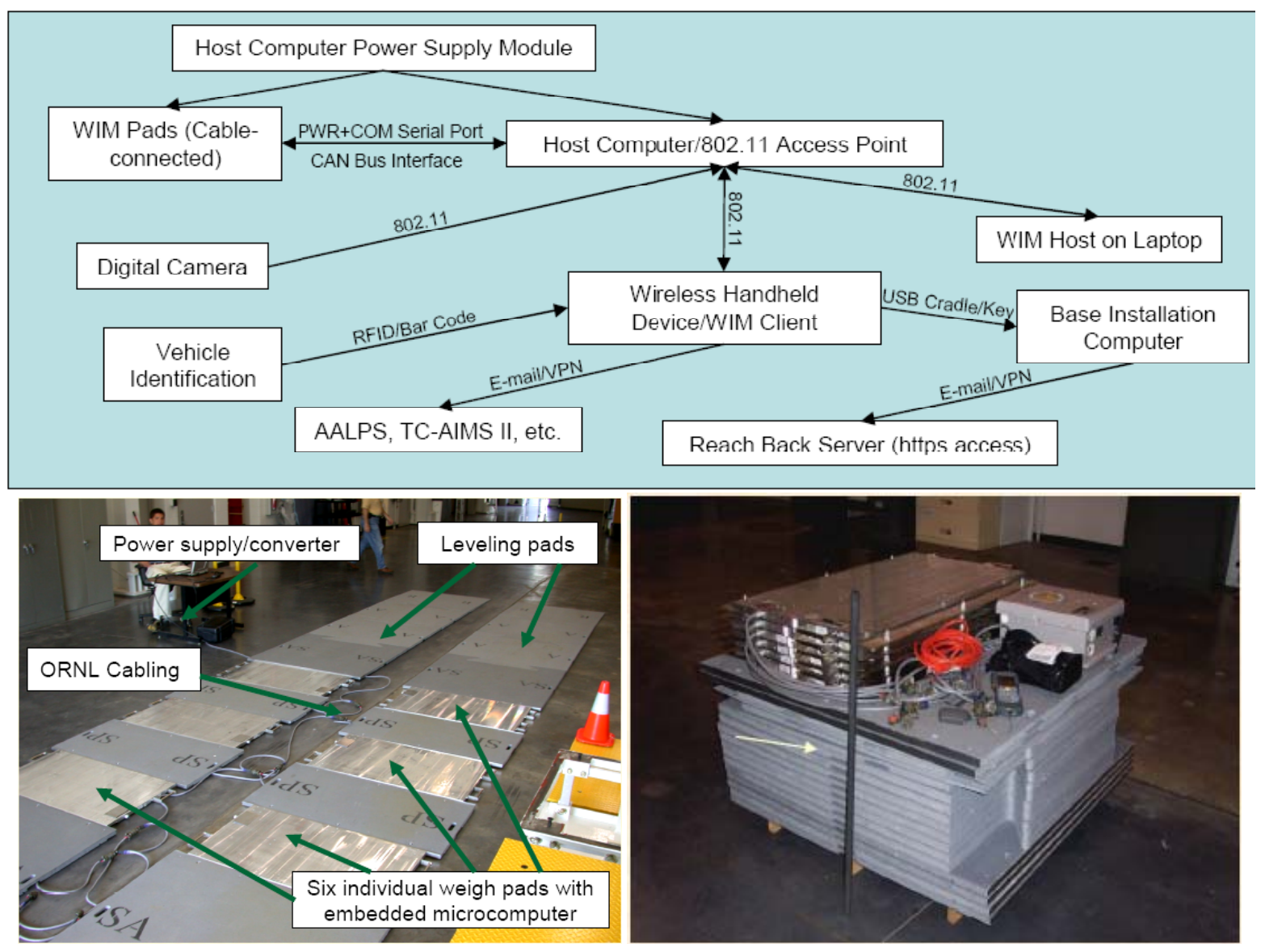

Figure 1. Weight measurement components and communication interfaces. 


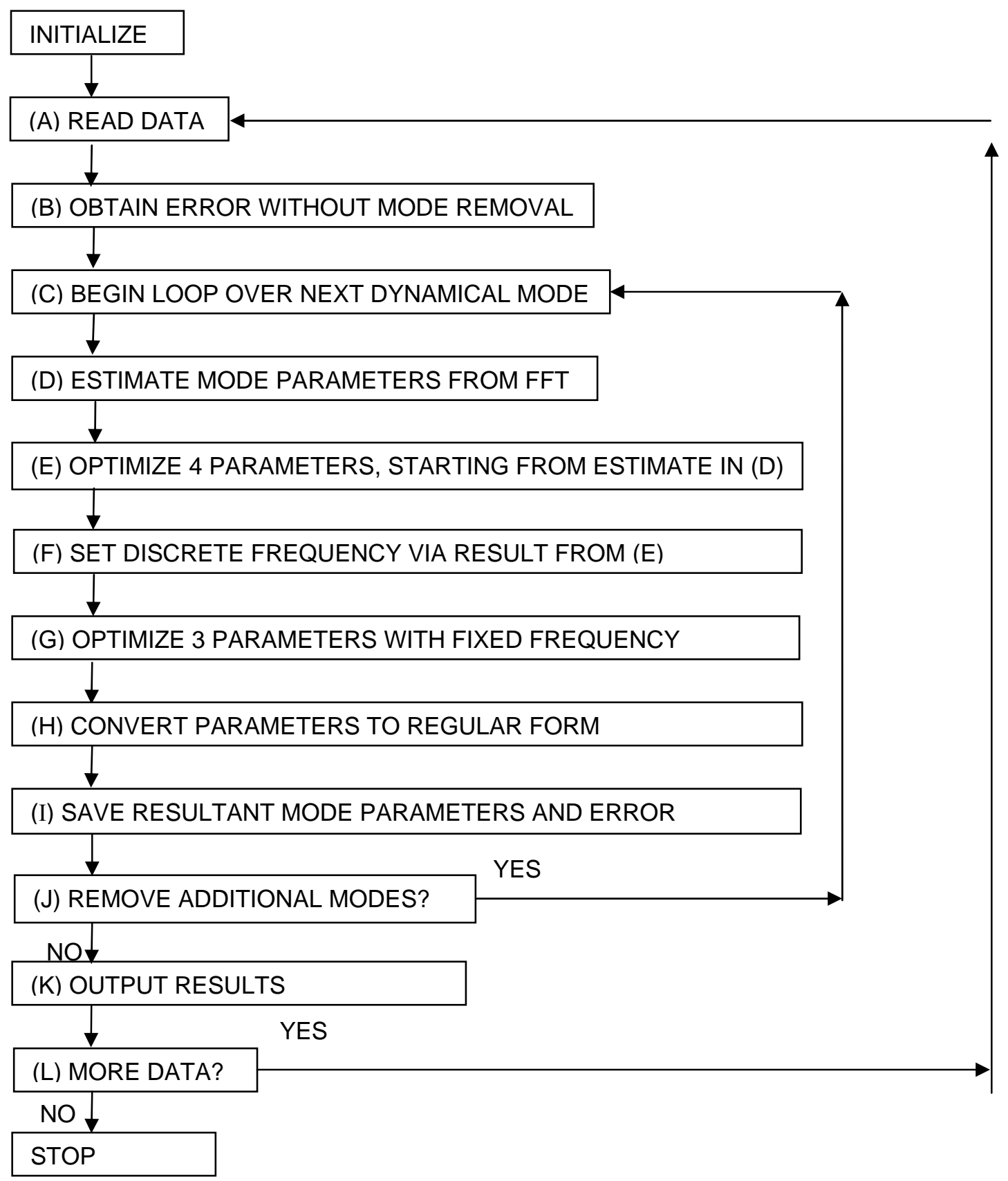

Figure 2. Flow diagram for nonlinear analysis. The letters in each box refer to the corresponding description in the text of Sect. 3. 

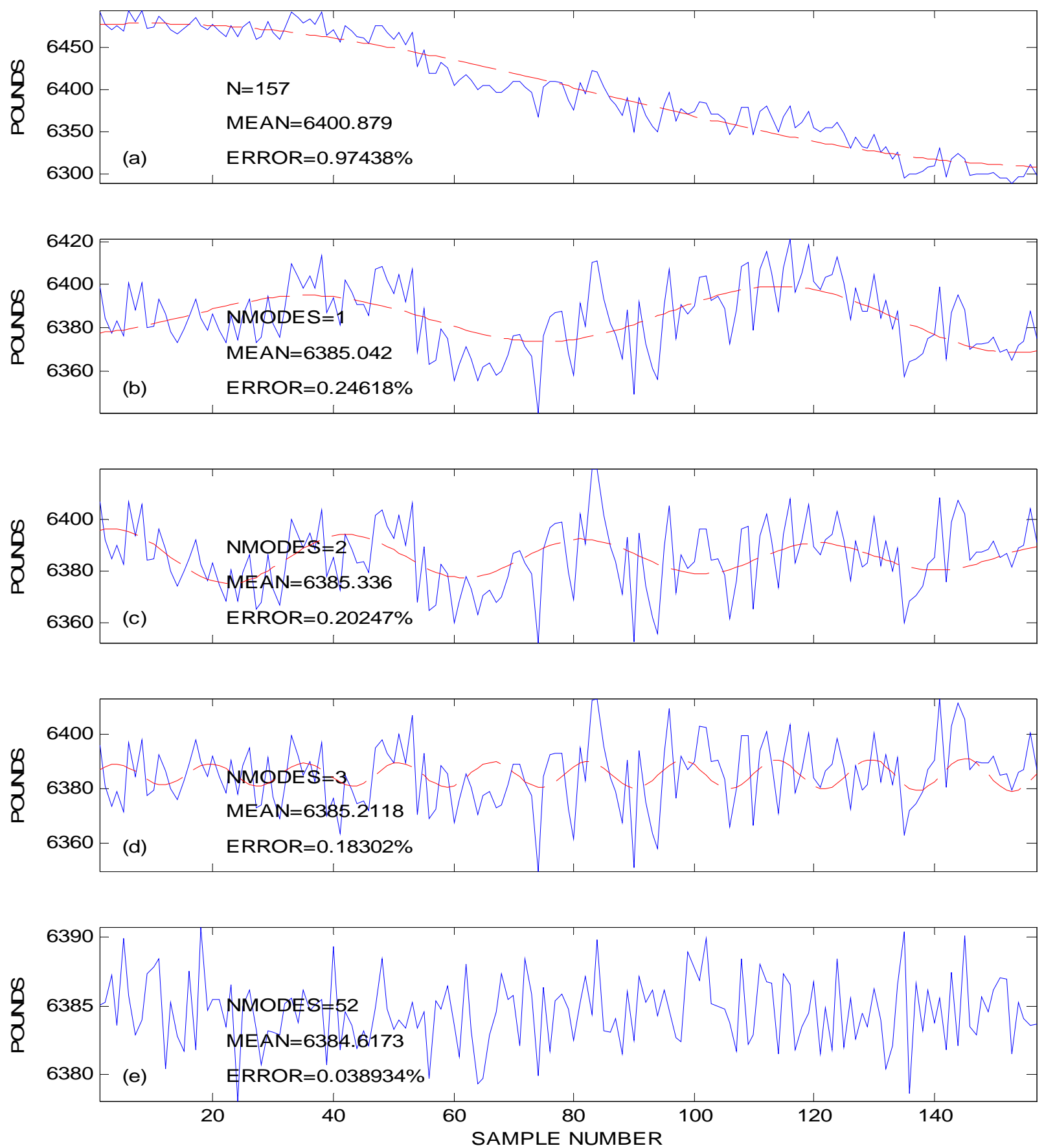

Figure 3. Time-serial weight measurements versus time (weight sample number, i) for (a) the unfiltered (raw) weight data (solid, blue curve) and the first oscillatory mode that the filtering method determined as the best low-order fit to the data (dashed, red curve), also showing the number of data points ( $N=157$ ), mean weight value (MEAN), and resultant (unfiltered) measurement error (ERROR); (b) the residual weight (solid, blue curve) after removal of the first oscillatory mode (NMODES=1) from subplot (a), and the second oscillatory mode (dashed, red curve) that is removed with the corresponding mean and error. In the same fashion, subsequent subplots (c) - (d) show the resultant residual weight after removal of the previous mode(s) and the next oscillatory mode that is removed with the corresponding mean and error. Subplot (e) shows the residual time variation, mean, and error after removal of all (52) modes. 

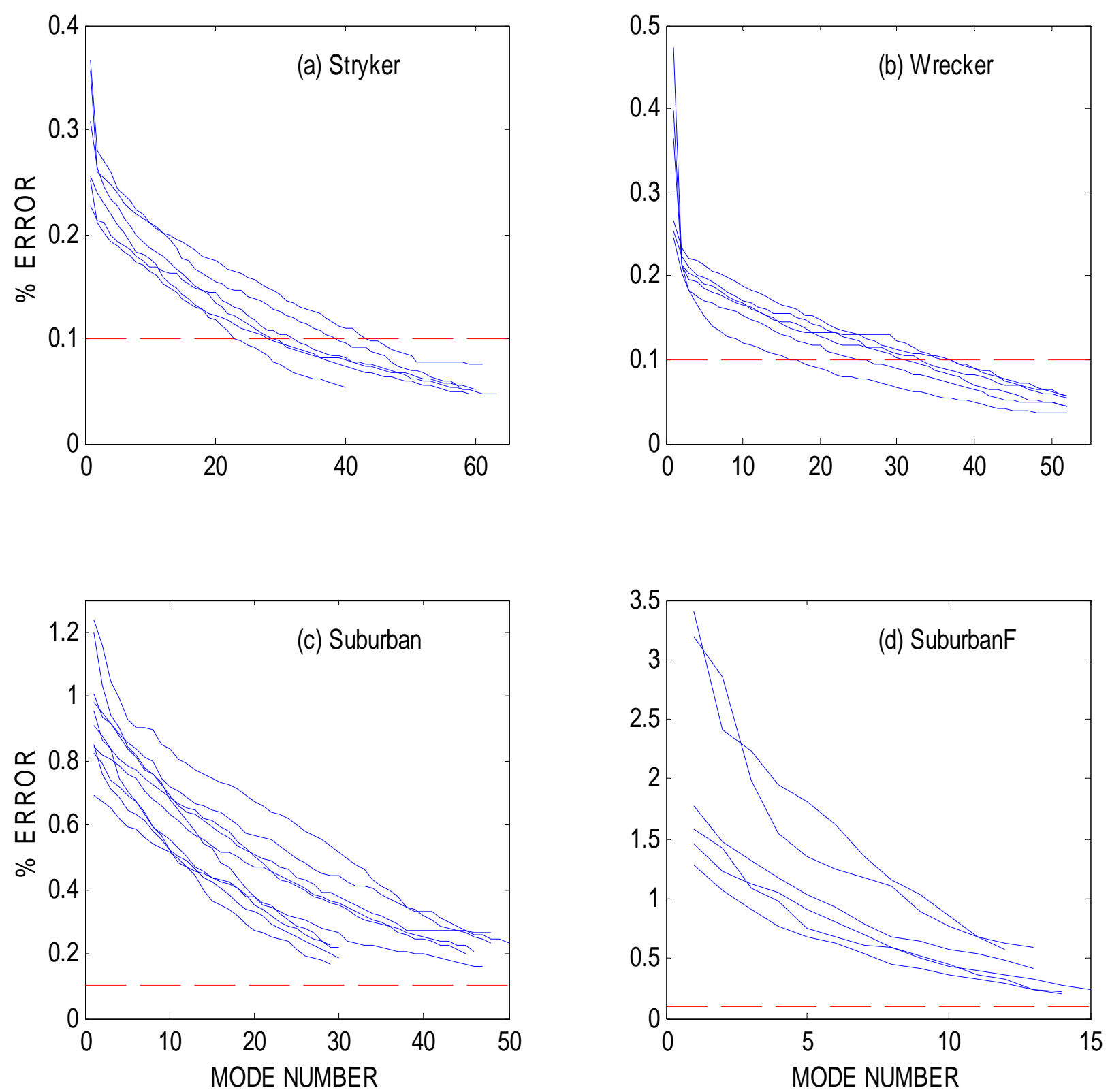

Figure 4. Decrease in residual (filtered) WIM error versus mode number for each of the four vehicle series in comparison to the $0.1 \%$ error limit for certifiable weights (dashed red line): (a) Stryker armored vehicle, (b) military wrecker vehicle, (c) unloaded Suburban, and (d) Suburban with 200 pounds of load. 


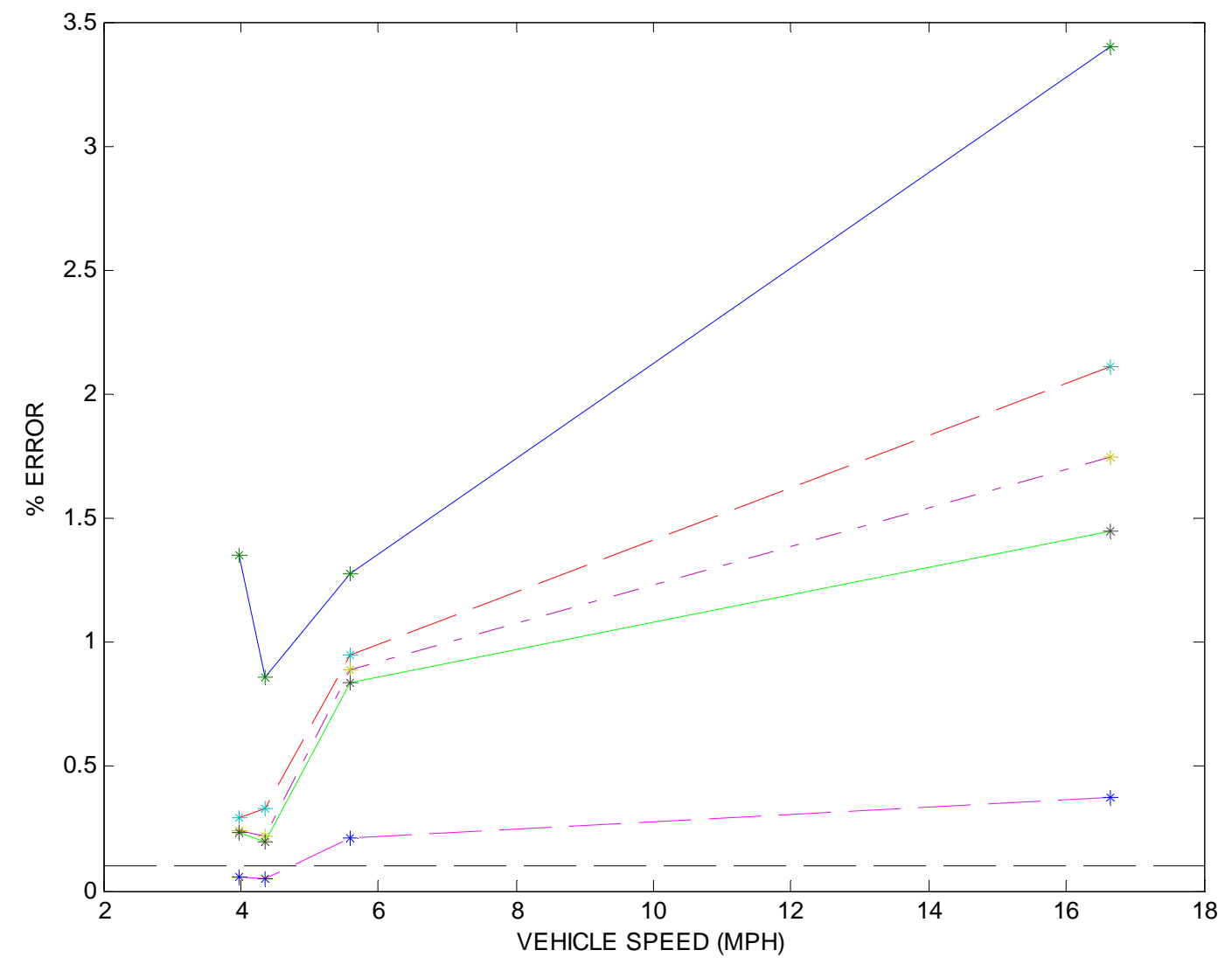

Figure 5. Average percent error in the WIM vehicle weight versus vehicle speed. Each curve shows error values from a column of Table 2, as follows: solid blue curve for no mode filtering, $e(\mathrm{u})$; dashed red curve(- -) for removal of one mode, $e(1)$ in Table 2; purple chain-dashed curve (-.-) for removal of two modes, $e(2)$ in Table 2; solid green curve for removal of three modes, $e(3)$ in Table 2; and dashed magenta curve (- -) for removal of $M$ modes, $e(M)$ in Table 1 . The horizontal black dashed curve (- -) indicates the $0.1 \%$ error level for certifiable weight measurements. 

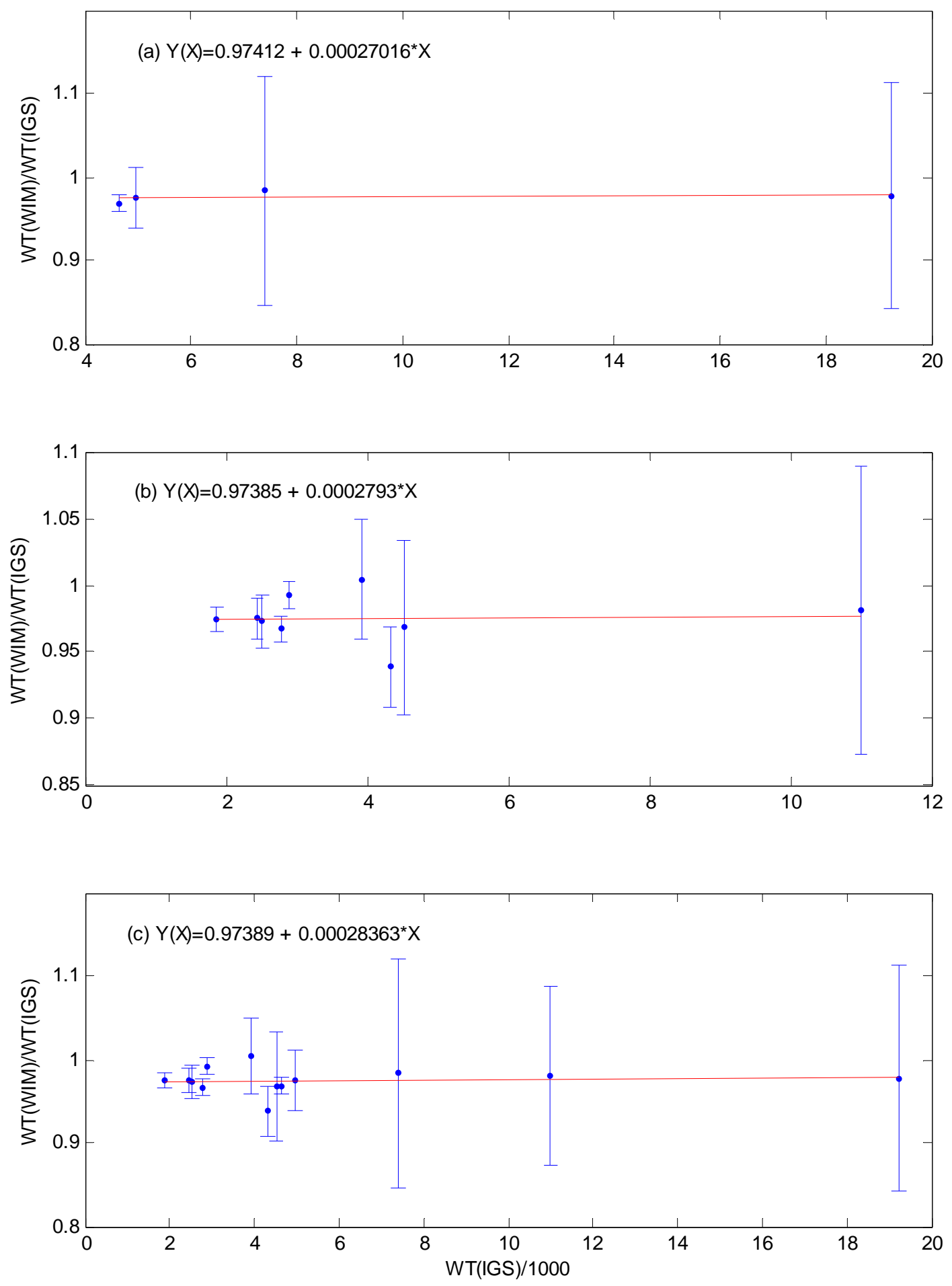

Figure 6. (WIM weight)/(IGS weight) versus IGS weight for (a) total weights, (b) single-axle weights, and (c) combination of (a) and (b). Straight-line fits for each set of data is shown for reference, along with the corresponding fitting parameters. 

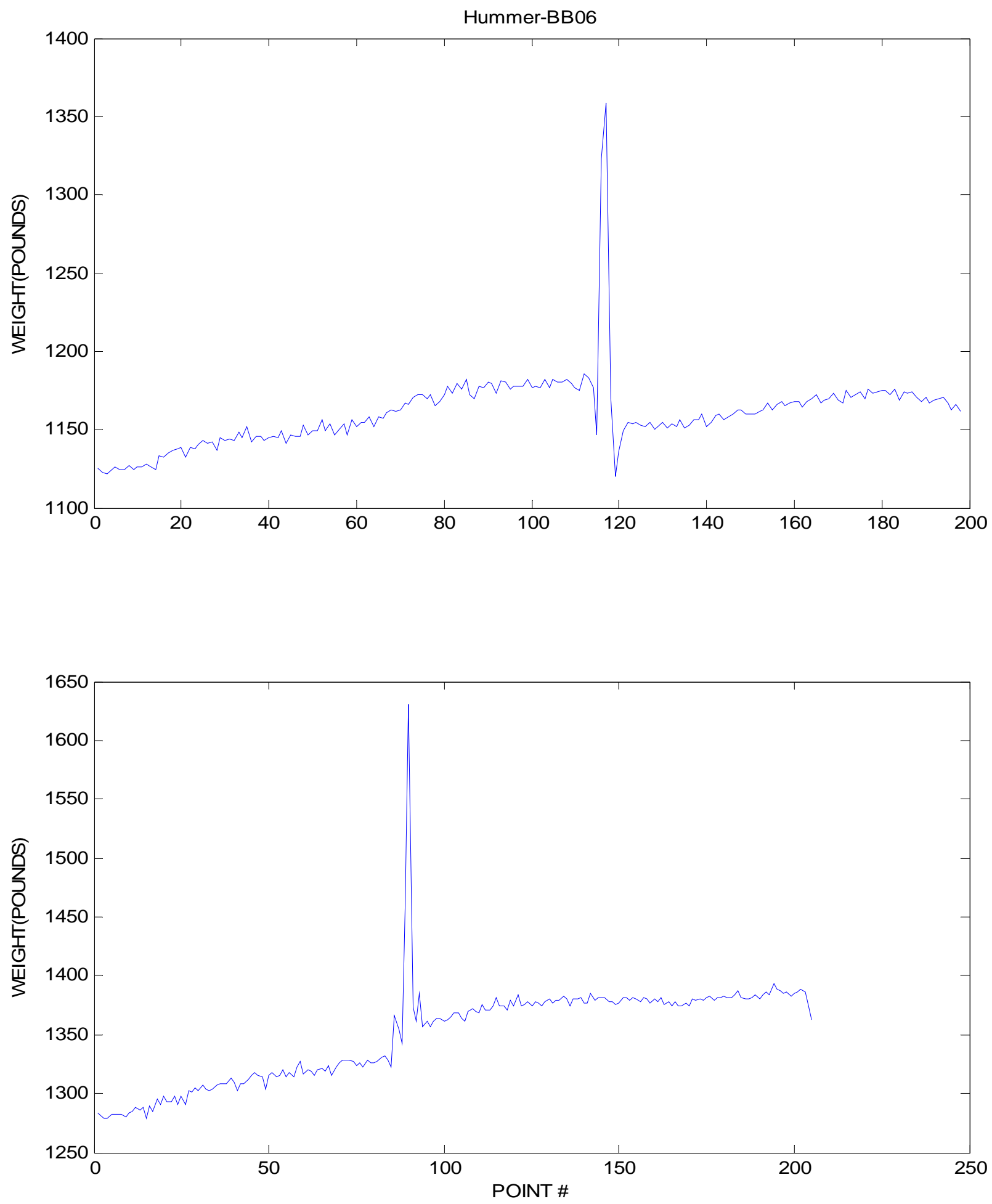

Figure 7. Raw Weight Data for Hummer-BB06 Dataset (see text for discussion). 


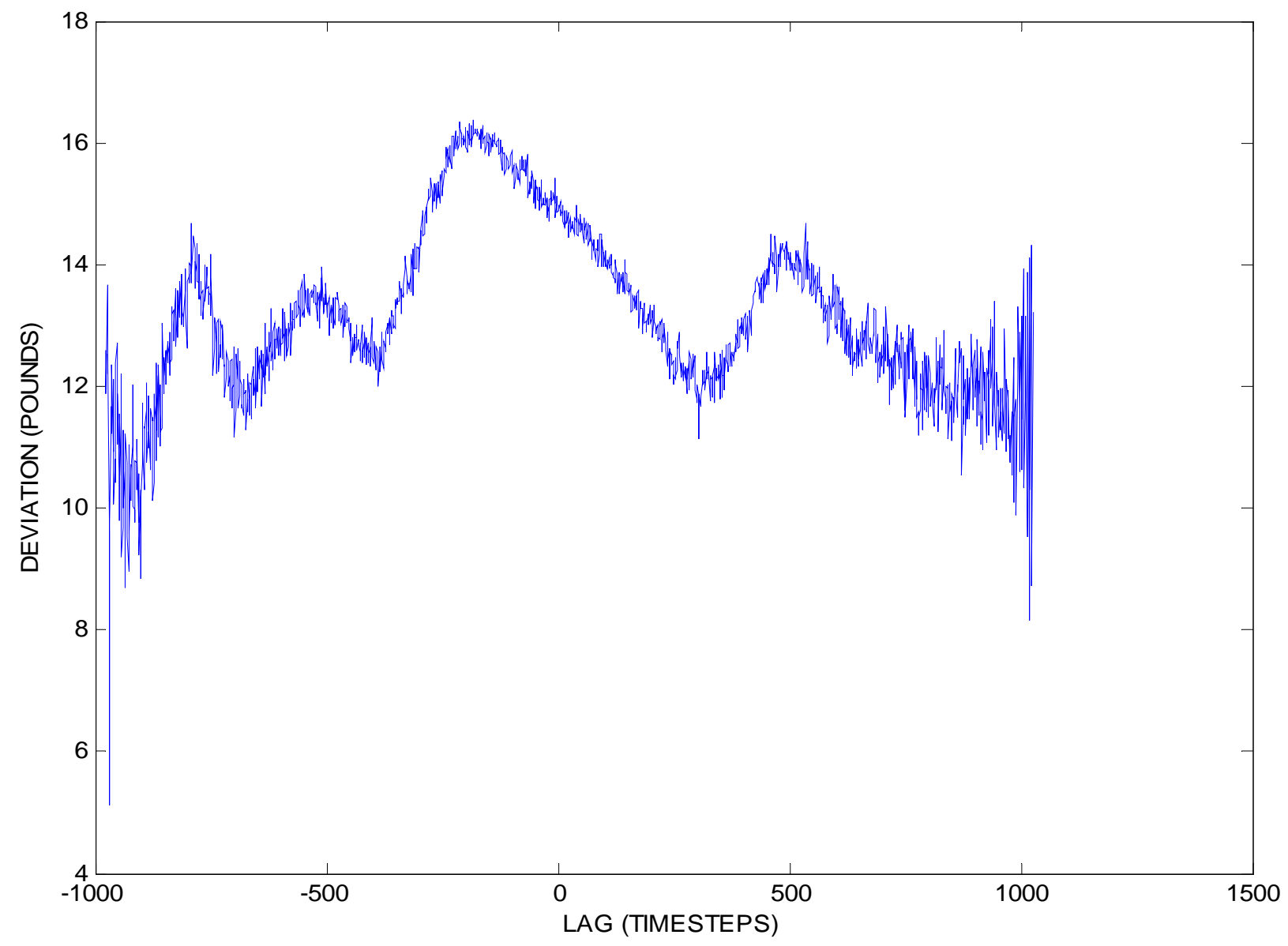

Figure 8. Sample standard deviation in the total WIM weight versus the time lag between the frontand rear-axle datasets for the Caravan-02 dataset without any clear minimum. See text for discussion. 

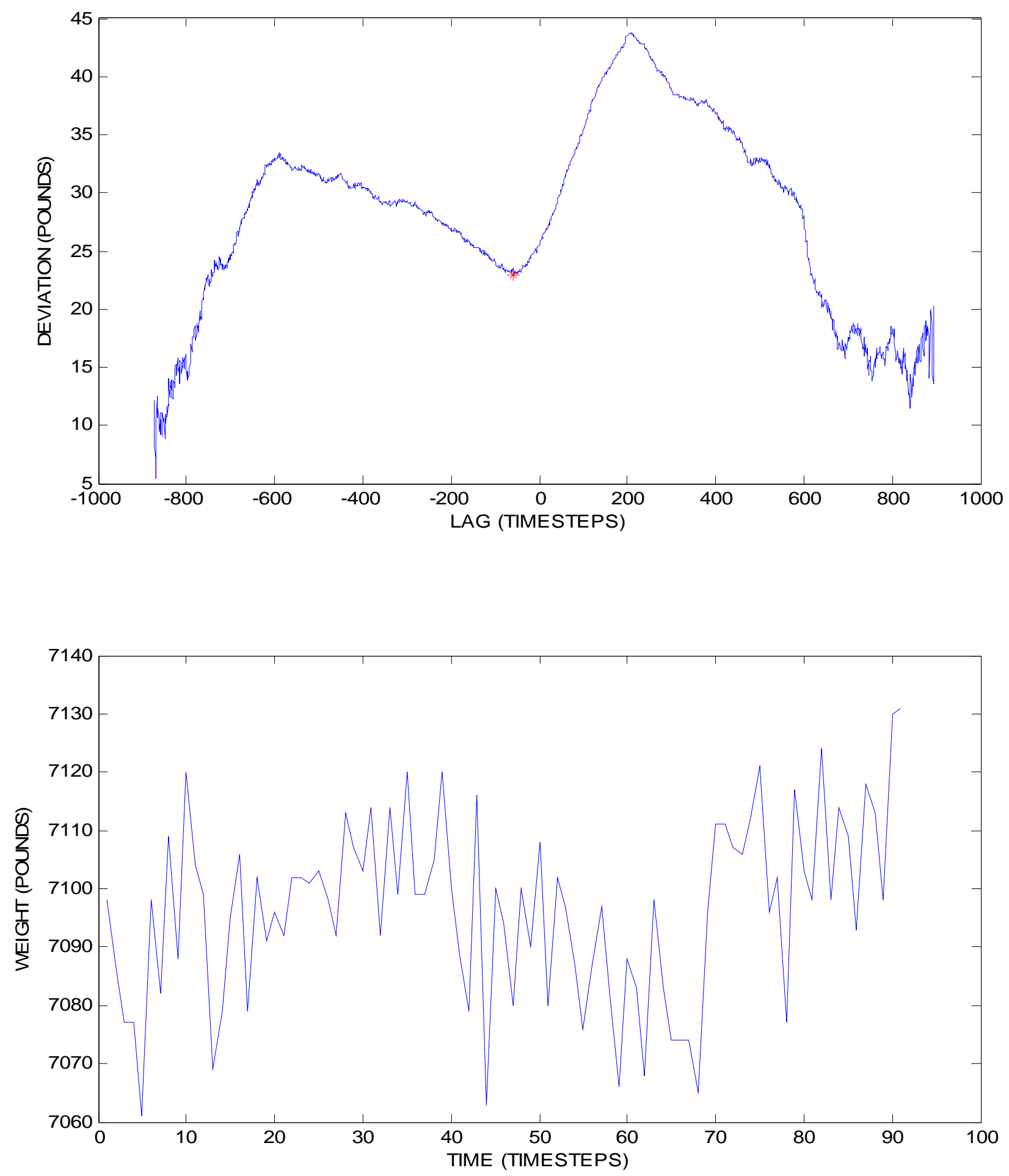

Figure 9. Sample standard deviation in the total WIM weight versus the time lag between the frontand rear-axle datasets for the F250-01 dataset with a clear minimum (red star in top plot) between two strong maxima; resultant total-vehicle weight versus time for the time-lag (bottom plot). See text for discussion. 

Appendix B

MATHEMATICAL DETAILS OF WIM ANALYSIS 



\section{APPENDIX B: MATHEMATICAL DETAILS OF WIM ANALYSIS}

This appendix describes the mathematical details of the WIM analysis to obtain the spacing of the vehicle axles for determination of the longitudinal center of balance. This analysis relies on discrete measurements as each wheel of the vehicle passes over the weigh pads. The specific measurements are the wheel weight and the time that the wheel is at the center (wheel-on-center time) of the weigh pad along with the speed of the wheel when it is on the center of the pad.

Some mathematical notation must first be defined. The weigh pads (WP) are labeled with the index, $i$, as shown in Figure B-1. The systematic placement of the numbers is shown for clarity, but may generally be in any arbitrary order. Six weigh pads are shown in the example of Figure B-1, but up to eight weigh pads are allowed by the present WIM software. The position of the $i$-th weigh pad along the direction of travel is denoted as $D_{i}$, and is fixed by the interlocking assembly with the spacing pads (SP), spacer-approach (SA) pads, and approach pads (AP).

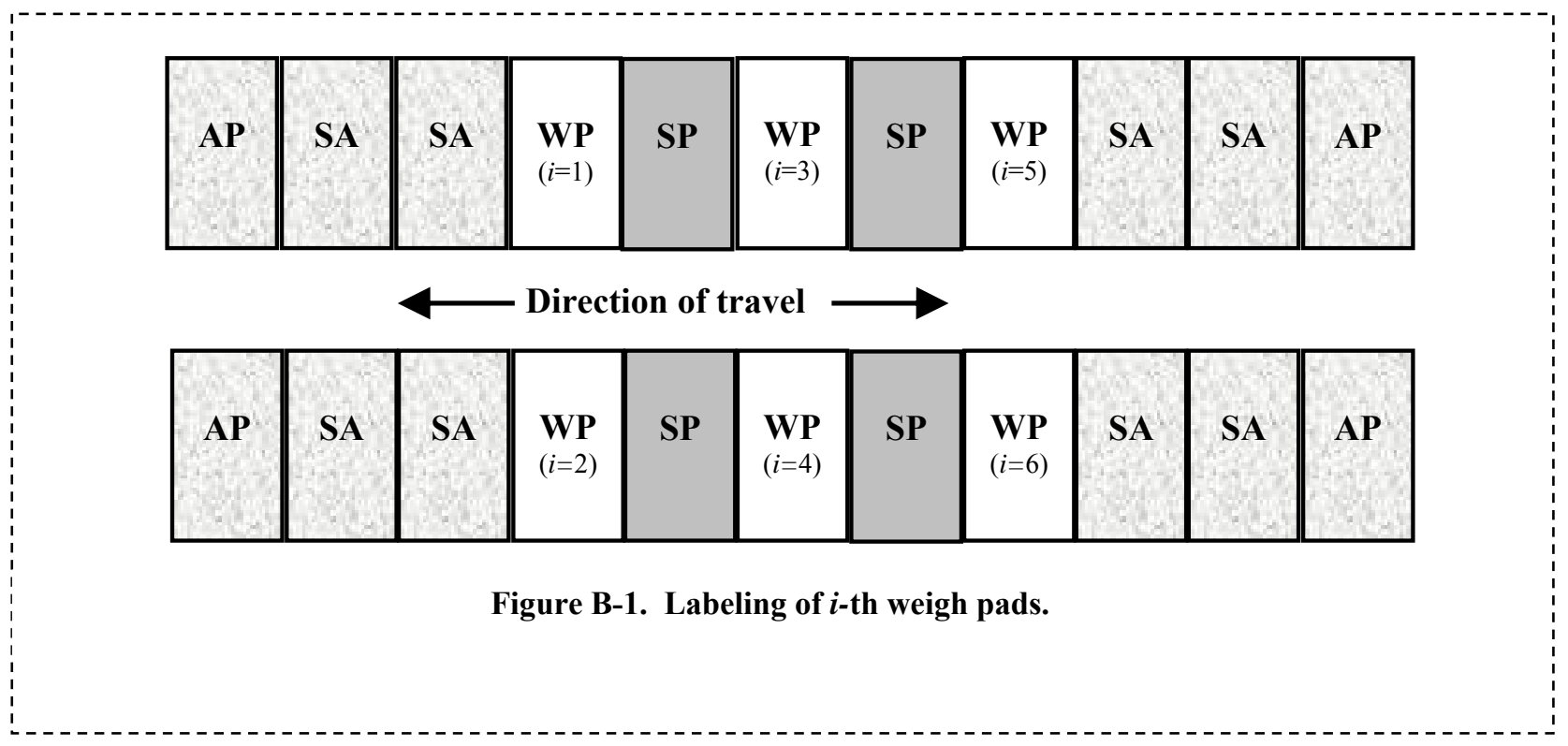

The vehicle axles are labeled with the index, $j$. Then, $j=1$ labels the first (front) axle; $j=2$ labels the second axle, and so on to the last (rear-most) axle. The position of the $j$-th axle along the vehicle length is then denoted as $A_{j}$.

One set of pads can be shifted along the direction of travel, relative to the other set. This shift is denoted by $S$, and applies to the right side (relative to the left side), as viewed from a vehicle moving along the direction of travel. This choice of "sides" is labeled by the index, $k$. Namely, $k=0$ labels the left side, and $k=1$ labels the right side. These definitions facilitate the subsequent mathematical description.

The weigh pad measurements are used to determine the vehicle position, as follows. The wheel-oncenter location $\left(x_{i j k}\right)$ is at the $i$-th pad for the $j$-th axle on the $k$-th side:

$$
x_{i j k}=D_{i}+A_{j}+S \times k .
$$


The corresponding time of this position measurement is $t_{i j k}$, for which the mathematical notation is:

$$
x\left(t_{i j k}\right)=x_{i j k} .
$$

The vehicle has a large momentum, and thus has a smoothly varying speed, so that higher order derivatives can be ignored without loss of accuracy. Therefore, this analysis assumes that the vehicle position can be approximated by a low-order polynomial function of time:

$$
x\left(t_{i j k}\right) \approx \sum_{n=0}^{m} a_{n} t_{i j k}^{n}
$$

The symbol, $\sum$, denotes a summation over the polynomial terms. The $a_{0}$-term in Eq. (B.3) has no time dependence, and corresponds to a position shift that is redundant with one of the axle locations. Thus, the analysis uses $a_{0}=0$. Eqs. (B.1) - (B.3) can be combined into a more complete form:

$$
\sum_{n=1}^{m} a_{n} t_{i j k}^{n} \approx x\left(t_{i j k}\right)=x_{i j k}=D_{i}+A_{j}+S \times k
$$

The relevant parts of Eq. (B.4) are the left-most term (polynomial for the vehicle's position as a function of time) and the right-most expression (wheel location), which (B.4) can be simplified to give:

$$
\left(\sum_{n=1}^{m} a_{n} t_{i j k}^{n}\right)-A_{j}-S \times k \approx D_{i} .
$$

Equation (B.4) is a system of simultaneous linear equations. The unknown coefficients, $\left\{a_{n}, A_{j}, S\right\}$, are grouped together on the left-hand side, and must be determined by the analysis. The weigh-pad positions, $D_{i}$, are fixed by their interlocking assembly with the spacing pads, as discussed above. For example, measurements by a WIM system with $I$ pads of a vehicle with $J$ axles yields $I \times J$ measurement values of the times, $t_{i j k}$, for the left-hand side of Eq. (B.5), or twelve values for a six-pad system and a two-axle vehicle. Experience shows that a low-order polynomial (e.g., $n=3$ ) is typically adequate. Thus, Eq. (B.5) is an over-determined system, for which an advanced method of solution is required.

A least-squares fitting procedure is appropriate to solve Eq. (B.5) by subtracting the $D_{i}$ term from both sides, leaving zero on the right-hand side (RHS). Exact equality is not possible for this overdetermined system, but near-equality is found by minimizing the function:

$$
F=\sum_{i j k}\left[\left(\sum_{n=1}^{m} a_{n} t_{i j k}^{n}\right)-\left(D_{i}+A_{j}+S \times k\right)\right]^{2} .
$$

The minimum possible value for $F$ is zero, which is consistent with equality in Eq. (B.5). Minimization of $F$ with respect to $a_{n}$ corresponds to $\partial F / \partial a_{n}=0$, which yields: 


$$
\sum_{i j k}\left[\left(\sum_{n=1}^{m} a_{n} t_{i j k}^{n+h}\right)-\left(A_{j}+S \times k\right) t_{i j k}^{h}\right]=\sum_{i j k} D_{i} t_{i j k}^{h} .
$$

The RHS is known from the pad locations, $D_{i}$, and the pad measurements of the times, $t_{i j k}$, for the wheel passages. The value of the index, $h$, has a range from 1 to $m$. Equation (B.7) expands into three equations for a cubic (third order) fit for the vehicle location, as an example:

$$
\begin{aligned}
& \sum_{i j k}\left[\left(\sum_{n=1}^{m} a_{n} t_{i j k}^{n+1}\right)-\left(A_{j}+S \times k\right) t_{i j k}\right]=\sum_{i j k} D_{i} t_{i j k} . \\
& \sum_{i j k}\left[\left(\sum_{n=1}^{m} a_{n} t_{i j k}^{n+2}\right)-\left(A_{j}+S \times k\right) t_{i j k}^{2}\right]=\sum_{i j k} D_{i} t_{i j k}^{2} . \\
& \sum_{i j k}\left[\left(\sum_{n=1}^{m} a_{n} t_{i j k}^{n+3}\right)-\left(A_{j}+S \times k\right) t_{i j k}^{3}\right]=\sum_{i j k} D_{i} t_{i j k}^{3} .
\end{aligned}
$$

Minimization of $F$ with respect to $A_{j}$ corresponds to $\partial F / \partial A_{j}=0$, which yields:

$$
\sum_{i j k}\left[\left(\sum_{n=1}^{m} a_{n} t_{i j k}^{n}\right)-\left(A_{j}+S \times k\right)\right]=\sum_{i j k} D_{i} .
$$

Minimization of $F$ with respect to $S$ corresponds to $\partial F / \partial S=0$, which yields:

$$
\sum_{i j k}\left[\left(\sum_{n=1}^{m} a_{n} t_{i j k}^{n}\right)-\left(A_{j}+k\right)\right]=\sum_{i j k} D_{i} .
$$

This last equation is meaningful only when $k=1$, allowing simplification to:

$$
\sum_{i j k}\left[\left(\sum_{n=1}^{m} a_{n} t_{i j k}^{n}\right)-\left(A_{j}+S\right)\right]=\sum_{i j k} D_{i}, \text { for } k=1 .
$$

Equation (B.9) has a sum over all the terms with $k=0$ and $k=1$, while Eq. (B.11) holds only for $k=$ 1. Consequently, Eqs. (B.9) and (B.11) are both included in the linear system of equations that determine the best parameter set. An additional set of equations can be obtained for the vehicle speed, $v$, by differentiating Eq. B.3:

$$
v=\frac{\partial x\left(t_{i j k}\right)}{\partial t} \approx \frac{\partial}{\partial t}\left(\sum_{n=0}^{m} a_{n} t_{i j k}^{n}\right)=\sum_{n=1}^{m} n a_{n} t_{i j k}^{n-1} .
$$

Equation (B.12) allows estimation of the vehicle speed, $v_{i j k}$, at each value of time, $t_{i j k}$. Consequently, Eq. (B.12) also can be rewritten into a function for minimization: 


$$
G=\sum_{i j k}^{m} \sqrt{V_{i j k}-\sum_{n=1} n a_{n} t_{i j k}^{n-1}} .
$$

Note that Eq. (B.13) is a function of speed and time, but not of the axle spacings, $A_{j}$, or of the pad-set shift, S. The polynomial coefficients, $a_{n}$, and the speed values, $v_{i j k}$, are obtained from solving Eq. (B.13). As before, minimization of $G$ requires $\partial G / \partial a_{n}=0$, which yields:

$$
\sum_{i j k}\left(\sum_{n=1}^{m} n a_{n} t_{i j k}^{n+h-2}\right)=\sum_{i h k} v_{i j k} t_{i j k}^{h-1} .
$$

The value of the index, $h$, has a range from 1 to $m$. Equation (B.14) expands into three equations for a cubic (third order) fit for the vehicle speed in this example:

$$
\begin{aligned}
& \sum_{i j k}\left(\sum_{n=1}^{m} n a_{n} t_{i j k}^{n-1}\right)=\sum_{i h k} v_{i j k} . \\
& \sum_{i j k}\left(\sum_{n=1}^{m} n a_{n} t_{i j k}^{n}\right)=\sum_{i h k} v_{i j k} t_{i j k} . \\
& \sum_{i j k}\left(\sum_{n=1}^{m} n a_{n} t_{i j k}^{n+1}\right)=\sum_{i h k} v_{i j k} t_{i j k}^{2} .
\end{aligned}
$$

Equations (B.12)-(B.15) have units of speed, while Eqs. (B.1)-(B.11) have units of distance. Consistent units for all of the equations are needed for a solution, and can be obtained by multiplying both sides of Eqs. (B.15a)-(B.15c) by some time value, $\tau$, which is chosen as $\sum t_{i j k}$ with the sum over all possible values of the set, $\{i j k\}$. Determination of the unknown coefficients, $\left\{a_{n}, A_{j}, S\right\}$, then is by the simultaneous solution of the Eqs. (B.8), (B.9), (B.11), and (B.15) via standard matrix analysis for the vehicle weight. Two weigh pads do not provide enough data to solve the system of equations using position only [Eqs. (B.8), (B.9), (B.11)] and require the inclusion of the measured speeds [Eqs. (B.15)] as additional input. Adequate data is available to solve these equations for four or more pads (e.g., four, six, and eight weigh pads) using only the position times [Eqs. (B.8), (B.9), (B.11)]. For this situation, only the position information is used to solve for the unknowns and then the speeds are checked for consistency with this solution. This approach in practice produces more meaningful results as the speed measurements can have a much larger error associated with them under certain circumstances.

We next discuss the analysis of measurements from a single weigh pad. A practical matter is the conversion of analog measurements to digital values (A-to-D conversion) with 12 bits of precision, corresponding to $2^{12}(=4,096)$ discrete values. The pad-level sensor is calibrated to a maximum of 17,000 pounds. Thus, the digital value is limited by a precision of $(17,000$ pounds $) /(4,096$ counts $)$ or roughly 4.2 pounds per count. Each sensor has eight load cells with locations as shown in Fig. B-2. Each load cell has a maximum calibration error of \pm 50 pounds due to hysteresis and non-linearity. This error corresponds to a typical value of $\sigma_{\text {LOADCELL }} \leq 25$ pounds. Then, the net sensor accuracy across all eight of these load cells is $\sigma_{\text {SENSOR }}=8^{1 / 2} \times \sigma_{\text {LOADCELL }}=71$ pounds (accuracy), which is much larger than the measurement precision (4.2 pounds). However, the major part of the load is distributed over only a few cells, thus reducing the final error. This analysis shows that the weight 
measurement is limited by the sensor accuracy (71 pounds), not by the A-to-D precision of 12 bits (4.2 pounds). Consequently, any single-tire weight has a sample standard deviation, $\sigma=71$ pounds. Any single-axle weight has $\sigma=2^{1 / 2} \times 71=100$ pounds. The total weight value of $J$-axle vehicle then has $\sigma=J^{1 / 2} \times 100$ (e.g., $\sigma=173$ pounds for a three axle vehicle). In each case, these values of $\sigma$ arise from the underlying calibration accuracy of the weigh-pad load cells. (In practice distributed loads also fall within the $50 \mathrm{lb}$ error boundary for the entire pad.)

A mico-computer in each weigh pad acquires the data from each load cell, performs the A-to-D conversion at 1,000 times per second $(1 \mathrm{kHz})$, and reports the results to the host computer. The MC12S series 8/16-bit micro-computer for this data acquisition and analysis has a processor speed of $34 \mathrm{MHz}$. The double arrow in Fig. B-2 indicates the direction of vehicle traversal across the weigh pad. The dashed line in Fig. B-2 indicates the weigh-pad centerline.

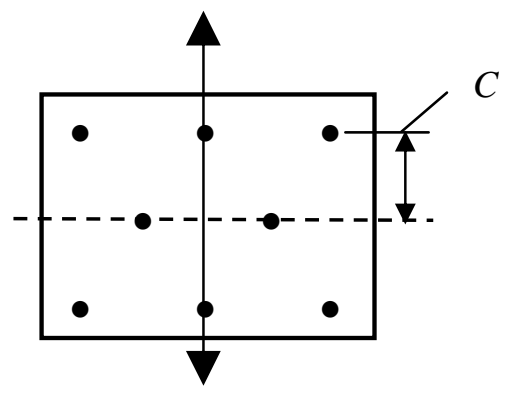

Figure B-2. Locations ( $\bullet$ ) of eight load cells in each WIM weigh pad (24” x 42").

The weight distribution among the load cells is used to determine the location, $X$, of the wheel center on the weigh pad, relative to the centerline. Figure B-2 also shows that three load cells are located at $x$ $=+C$ (above the centerline), two lie on the centerline $(x=0)$, and three occur below the centerline at $x$ $=-C$. The $g$-th load cell measures a weight, $w_{g}(t)$, at time, $t$. The total weight of the tire, $W(t)$, on the pad at time, $t$, is simply the sum of the load cell values:

$$
W(t)=\sum_{g} w_{g}(t)
$$

The moment, $X(t)$ of this single-pad weight measurement at time, $t$, is:

$$
X(t)=\left[\sum_{g} x_{g} w_{g}(t)\right] / W(t) .
$$

Here, the value of $x_{g}$ is $+C, 0$, or $-C$, depending on the load cell's location in Fig. B-2. (A similar lateral moment is also computed but is only used to check that the tire is fully on the pad.) A linear least-squares fit versus time is used for $X(t)$ :

$$
X(t) \approx P+Q t
$$

The weigh-pad length in the direction of travel is $24 "$. A tire footprint in the direction of travel is typically 12 ". Consequently, only data from the central $10 "-12$ " of travel, $-C \leq X(t) \leq+C$, is used in the fit of Eq. (B.18) to assure that the tire is positioned on the weigh pad. The magnitude, $|Q|$, of the slope from this fit gives an estimate the vehicle's speed, $V=|Q|$. The sign of Q tells the direction of 
the vehicle's motion (left side is positive and right negative.) The quality of this fit is measured by the root-mean-squared (RMS) error, $\varepsilon$, between the actual values of tire position, $X(t)$, and the fit, $P+Q t$ :

$$
\varepsilon=\sqrt{\sum_{t}[X(t)-(P+Q t)]^{2} / N}
$$

The symbol, $N$, denotes the number of time samples $(N \sim 200-400)$ as the tire traverses the pads. The tire traverses the center, $X=0$, of $i$-th pad for the $j$-th axle on the $k$-th side at the time, $t_{i j k}$, which can be obtained from Eq. (B.18) for $X\left(t_{i j k}\right)=0$ as:

$$
t_{i j k}=-P / Q
$$

This time on center, $t_{i j k}$, is used in the previous analysis of vehicle weight. Moreover, the measurements of total-tire weight, $W(t)$, provide a time-integrated weight from $i$-th pad for the $j$-th axle on the $k$-th side:

$$
W_{i j k}=\sum_{t} W(t) / N
$$

The corresponding sample standard deviation in weight, $\sigma_{i j k}$, is obtained from the equation:

$$
\sigma_{i j k}=\sqrt{\sum_{t}\left[W(t)-W_{i j k}\right]^{2} /(N-1)} .
$$

Clearly, these results are obtained over the same center section of the pad as the moment to assure that the tire is fully on the pad. The results of this analysis from the $i$-th pad for the $j$-th axle on the $k$ th side are: (1) the vehicle speed, $V$, from the fit of Eq. (B.18); (2) the RMS error, $\varepsilon$, of the positionversus-time fit from Eq. (B.19); (3) the time on center, $t_{i j k}$, from Eq. (B.20); (4) the time-averaged weight, $W_{i j k}$, from Eq. (B.21); and (5) the corresponding estimate of the sample standard deviation in weight, $\sigma_{W}$, from Eq. (B.22). This analysis allows comparison of the vehicle speed, $V$, from the padlevel fit of Eq. (B.18) to the vehicle-level fit of speed, $v$, from Eq. (B.12). Moreover, an excess value of the RMS fitting error, $\varepsilon$, from Eq. (B.19) typically indicates that the particular run is flawed, and needs to be re-measured.

After a tire traverses the a pad, the micro-computer reports these pad-level results to the host computer, which combines them as follows. The weight from the $i$-th pad for the $j$-th axle is a sum of the tire weights on both sides $\left(\sum_{k}\right)$. The average weight, $W_{j}$, of the $j$-th axle across all of the weigh pads then is:

$$
W_{j}=\sum_{k=0}^{1} \sum_{i=1}^{I} W_{i j k} / I
$$

Here, the symbol, $I$, denotes the number of pad pairs (e.g., $I=3$ for 6 weigh pads). The corresponding sample standard deviation is:

$$
\sigma_{j}=\sqrt{\sum_{k=0}^{1} \sum_{i=1}^{I} \sigma_{i j k}^{2}} .
$$


The total vehicle weight, $W_{\text {тот }}$, is simply the sum of the axle weights:

$$
W_{\text {TOT }}=\sum_{j=1}^{J} W_{j} .
$$

Here, the symbol, $J$, denotes the number of axles, as before. The corresponding sample standard deviation, $\sigma_{W}$, in the total vehicle weight in a 2-pad system is:

$$
\sigma_{W}=\sqrt{\sum_{j=1}^{J} \sigma_{j}^{2}}
$$

For a larger system, we have multiple measurements for each tire weight. With these systems the standard deviation is obtained from the root-mean-square of the tire weights:

$$
E_{W}=B \sqrt{\sum_{k=0}^{1} \sum_{j=1}^{I} \sum_{j=1}^{J}\left(W_{i j k}-W_{j}\right)^{2}} .
$$

As before, $I$ denotes the number of pad pairs, and $J$ is the number of vehicle axles. $B$ is the correction factor for a Student's T-distribution for a 95\% confidence interval.

The results of the vehicle- and pad-level analyses are reported to the user by the host computer, as summarized in Table B.1. The default value for the error flags in Table B.1 is zero. If any of the limits in Table B.1 are exceeded (e.g., vehicle speed too fast), then the error flag in Table B.1 is set to 1 to flag the run as potentially "bad." Specifically, Table B.1 shows details of the filtering limits. At the client level (above the Host), the vehicle type is known. A corresponding table of limit values can be stored by vehicle type, thus providing consistency in the filtering process. These limits have been determined empirically from tests at Ft. Lewis during 2006 and subsequently refined further. The user can accept or ignore these error flags for final results. The limits in Table B.1 use two additional parameters that relate to those above. One is the average over the differences between the actual and fitted distances from Eq. (B.6):

$$
K=\sum\left[\left(\sum_{n=1}^{m} a_{n} t_{i j k}^{n}\right)-\left(D_{i}+S \times k\right)\right] /(I \times J) .
$$

The second is the average over differences between the actual and fitted speeds from Eq. (B.13):

$$
G=\sum_{i j k}^{m}\left(v_{i j k}-\sum_{n=1} n a_{n} t_{i j k}^{n-1}\right) /(I \times J) .
$$



Table B-1. Summary of WIM results

Variable Name
BadDistFit
BadSpdFit
BadDistRms
BadSpdRms
BadFitRms
BadTooFast
BadTooSlow
BadSpdDelt
BadStdWt
BadAveWt
BadCell
BadPadCt
BadAxlPn
MissingAxleData
AxleTimeOut
expected

$\underline{\text { Brief description of meaning }}$

average distance of actual from fit

average speed of actual from fit

RMS of distance to actual fit

RMS of speed to actual fit

combined above two

upper speed limit

lower speed limit

$\mathrm{min} /$ max speed difference

variation of weight between pads

bad average weight reported from pad

flag for bad load cell reading

odd number of operational pads

axle spacing too small

missing data from pads

fewer axles than requested $\underline{\text { Equation for constraint }}$

$K>0.001 "$

$L>0.20 \mathrm{mph}$

$\left[F /\left(I^{*} J\right)\right]^{1 / 2}>0.50^{\prime \prime}$

$\left[G /\left(I^{*} J\right)\right]^{1 / 2}>0.30 \mathrm{mph}$

$\left[(F+G) /\left(\mathrm{I}^{*} \mathrm{~J}\right)\right]^{1 / 2}>0.75$

$V>5.0 \mathrm{mph}$

$V<0.2 \mathrm{mph}$

$V_{\text {max }}-V_{\text {min }}>0.7 \mathrm{mph}$

$\varepsilon>1 \%$ for 2-pads; $E>5 \%$ for $\geq 4$ pads

bad A-to-D (e.g., over-/under-flow)

over-/under-flow from loadcell

odd number of pads reporting

$\left|A_{j}-A_{j \pm 1}\right|<10.0^{\prime \prime}$

$J<$ known axle number for each pad

$J=$ same for all pads, but less than 



\section{INTERNAL DISTRIBUTION}

1. R. K. Abercrombie

2. L. M. Hively

3. M. B. Scudiere

4. F. T. Sheldon

5. J. P. Trien

6. B. A. Worley

7. Central Research Library

8. ORNL Laboratory Records-RC

9. ORNL Laboratory Records-Office of Technical Information and Classification (OSTI) 